DIW BERLIN

Discussion

Papers
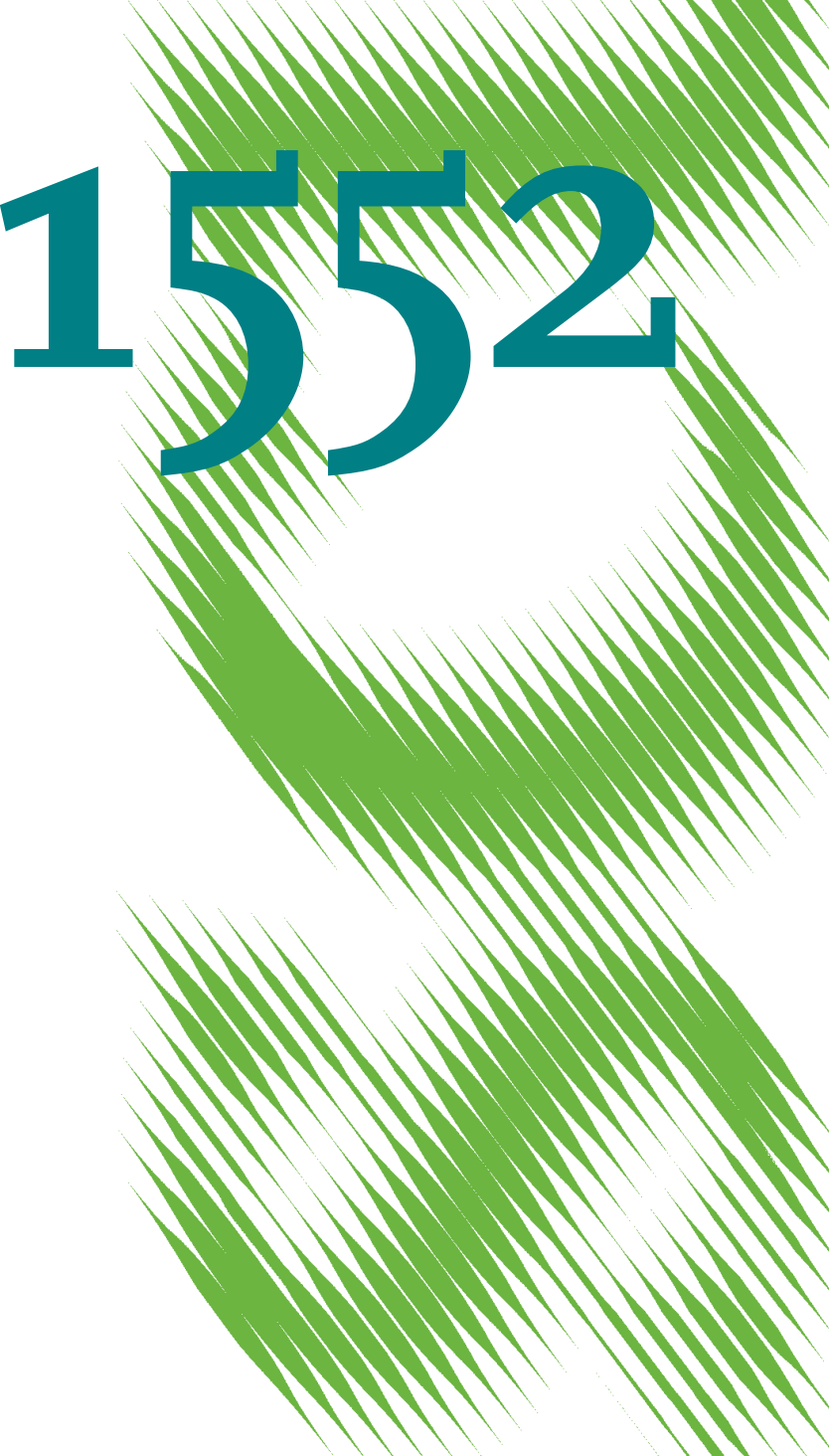

Equity Premium Prediction:

Are Economic and Technical Indicators Unstable? 
Opinions expressed in this paper are those of the author(s) and do not necessarily reflect views of the institute.

IMPRESSUM

(C) DIW Berlin, 2016

DIW Berlin

German Institute for Economic Research

Mohrenstr. 58

10117 Berlin

Tel. +49 (30) $89789-0$

Fax +49 (30) $89789-200$

http://www.diw.de

ISSN electronic edition 1619-4535

Papers can be downloaded free of charge from the DIW Berlin website:

http://www.diw.de/discussionpapers

Discussion Papers of DIW Berlin are indexed in RePEc and SSRN:

http://ideas.repec.org/s/diw/diwwpp.html

http://www.ssrn.com/link/DIW-Berlin-German-Inst-Econ-Res.html 


\title{
Equity Premium Prediction: Are Economic and Technical Indicators Unstable?
}

\author{
Fabian Baetje and Lukas Menkhoff
}

\begin{abstract}
We show that technical indicators deliver stable economic value in predicting the U.S. equity premium over the out-of-sample period from 1966 to 2014. Results tentatively improve over time and beat alternatives over a large continuum of sub-periods. By contrast, economic indicators work well only until the 1970s, but thereafter they lose predictive power, even when the last crisis is considered. Translating the predictive power of technical indicators into a standard investment strategy delivers an annualized average Sharpe ratio of 0.55 p.a. (after transaction costs) for investors who had entered the market at any point in time.
\end{abstract}

JEL-Classification: $\quad$ G17 (financial forecasting); G12 (asset pricing) Keywords: Equity premium predictability; economic indicators; technical indicators; break tests

We thank referees and participants at several workshops and seminars, in particular Guglielmo Maria Caporale, Ana-Maria Fuertes, Richard Payne and Maik Schmeling for their very useful comments.

Fabian Baetje, Department of Economics, Leibniz University Hannover, Königsworther Platz 1, D-30167 Hannover, Germany; e-mail: baetje@gif.uni-hannover.de.

Lukas Menkhoff, DIW Berlin (German Institute for Economic Research), 10108 Berlin, Germany, and HumboldtUniversity Berlin; e-mail: Imenkhoff@diw.de; tel. ++49 (0)30 89789435 


\section{Introduction}

There is a long-standing debate whether the equity premium is predictable or not. Whereas predictability seemed to be largely accepted for some time (e.g., Campbell and Shiller, 1988a,b, Fama and French, 1988, 1989, Cochrane, 2008), Goyal and Welch (2008) present strong evidence challenging the view of predictability. They show that standard economic indicators used for predicting equity returns perform poorly over time which is at least partly due to instability issues. In particular, a large share of the forecasting performance arises from the period up to the early 1970s but there is little evidence of predictability in later decades. Seen from this perspective, many earlier results in favor of predictability may be driven by specific samples but do not suggest systematic return predictability. Thus it is our prime goal to examine the stability of predictive performance that forecasting indicators deliver over time.

There are two recent developments which further motivate our analysis. First, economic indicators predict the equity premium quite well in crisis times which might lead to much improved forecasting results when including the recent crisis of 2008/09. Second, Neely et al. (2014) show that their universe of 14 technical trading rules is also able to predict the equity premium out-of-sample. The performance of these indicators is comparable to that of 14 conventional indicators which are based on economic reasoning, such as the "dividend-price ratio". Hence, expanding the sample period and the universe of predictors seems to allow for a more powerful test regarding the stability of return predictability compared to earlier literature, such as Goyal and Welch (2008).

Based on these arguments, we thoroughly examine the possible instability of economic and technical indicators for predicting the U.S. equity premium. Whereas both kinds of indicators provide a similar degree of predictive performance over the full sample (Neely et al., 2014), their degree of instability is completely different: Our main finding is that only technical indicators do provide stable economic value relative to the historical average (as a standard benchmark). Transforming this kind of equity premium prediction into a conventional investment strategy generates an annualized average Sharpe ratio of 0.55 p.a. (after transaction costs) for an investor who entered the market at any point in time since the mid 1960s. Reassuringly, this performance is tentatively increasing over time and thus stands in clear contrast to economic indicators which lost their predictive power after the 1970s, even when we consider the recent crisis period. 
Our data and procedures closely follow main studies in this field, in particular Goyal and Welch (2008) and Neely et al. (2014), in order to make our analysis directly comparable. We choose the same selection of 14 economic and 14 technical indicators to predict the equity premium over the sample period from 1966 to the end of 2014. Based on this (extended) replication of the earlier result in Neely et al. (2014) which shows forecasting power of economic and technical indicators over the full sample period, we implement various tests to uncover potential forecasting instability over time.

We start by applying the Goyal and Welch $(2003,2008)$ approach in order to assess predictive performance over time. In more detail, the first prediction is made for January 1966, and from there on the in-sample estimation period is extended month by month. (i) We find that predictive performance of economic indicators does not seem to improve when extending the sample by an additional nine years compared to Goyal and Welch (2008). (ii) When applying the same procedure to the set of technical indicators introduced by Neely et al. (2014), we also find unstable predictive performance; however, performance increased during the last decades. (iii) Obvious instability motivates us to examine the empirical relationship between the equity premium and the forecasting variables by conventional break tests. Results show break points for economic indicators (and hardly any for technical indicators) but empirical evidence of break-points is not consistent across various tests.

(iv) In order to account for instability in the forecasting process (as indicated by the Goyal and Welch-approach and break tests), we propose to neglect data from the distant past. Instead of using a fixed starting point and enlarging the sample period from there on (see Goyal and Welch, 2003, 2008), we use a fixed end-point and shorten the sample by successively shifting the initial estimation period through time; thereby we examine hundreds of overlapping sub-periods. This procedure introduces the idea of rolling windows but avoids unreliable results from a standard rolling window approach. Results confirm that economic indicators do not generate stable forecasting power (Goyal and Welch, 2008), also not at recent periods. By contrast, we show that technical indicators can forecast the equity premium even until the most recent decades.

(v) Finally, we apply this rolling recursive approach to assess the stability of forecasts by utility-based metrics. More specifically, we consider a mean-variance investor who optimizes his risk-return profile depending on the predicted equity premium. Performance is determined by the certainty equivalent return and the Sharpe ratio using various risk-aversion coefficients, transaction costs and constraints on portfolio weights. We find that technical 
indicators are able to beat alternative investment strategies in almost all relevant cases, in particular during most sub-periods. By contrast, the declining predictive ability of economic indicators translates into disappointing economic value for investment strategies.

Beyond its close relation to Neely et al. (2014) and also Goyal and Welch (2008), our research belongs to four broader strands of literature: We first refer to studies predicting the equity premium by economic indicators, such as the dividend-price ratio, as surveyed by Rapach and Zhou (2013). These studies are reflected and refined in the collection of papers summarized by Spiegel (2008), including Goyal and Welch (2008), Campbell and Thompson (2008), Cochrane (2008) and Lettau and Van Nieuwerburgh (2008). More recently, Rapach et al. (2010) suggested that combination measures of economic indicators may lead to better forecasting results. Second, our study is inspired by earlier works showing the usefulness of certain technical indicators for predicting stock returns, such as Brock et al. (1992), Brown et al. (1998), Lo et al. (2000) and Neely et al. (2014). Third, our main concern here is, however, not predictability as such but its potential instability. In a first step, we follow Rapach and Wohar (2006) and Paye and Timmermann (2006) testing for structural stability of predictive regression models. Our results provide evidence of structural instability, however, not always at the same point in time. In order to take account of breaks whose exact timing is unclear, we employ a recursive estimation setting based on rolling initialization periods. Fourth and finally, we evaluate the predictive performance in economic terms which provides a direct linkage to its practical usefulness. In this respect, we follow Cenesizoglu and Timmermann (2012) and Rapach and Zhou (2013), among others. Again, our main objective is not the economic value of certain strategies over the full sample but analyzing the instability of economic values over many sub-periods.

This paper is organized in five more sections. Section 2 informs about the approach and the data. Section 3 contains our examination of out-of-sample equity premium prediction, focusing on the analysis of instability. Results are assessed in Section 4 where we analyze the economic value from the preceding section. Further robustness tests are sketched in Section 5 and Section 6 concludes. 


\section{$2 \quad$ Approach and data}

This section provides background information for the research presented in later sections. It describes the forecasting approach (Section 2.1) and the data being used (Section 2.2).

\subsection{Forecasting approach}

Our empirical application is based on the typical specification for equity premium prediction, i.e.

$$
r_{t+1}=\alpha_{i}+\beta_{i} x_{i, t}+\varepsilon_{i, t+1}
$$

where $r_{t+1}$ is the equity premium at time $t+1$ and $x_{i, t}$ is the one-month lagged predictive variable stemming from a broad set of economic variables and technical trading rules, indexed by $i$. $\varepsilon_{i, t+1}$ denotes the corresponding equity premium innovation. In addition, we also make use of forecasting strategies which should yield superior prediction performance by addressing concerns of in-sample overfitting, model uncertainty and parameter instability (summarized by Rapach and Zhou, 2013). Specifically, we use forecasting strategies that incorporate information from the full set of predictor variables stemming from economic variables, technical indicators or both. We follow Neely et al. (2014) in this respect and estimate latent factor structure models, proposed by Stock and Watson (2002a,b). Regarding the number of principal components used in the predictive setting, we employ the Schwarz information criterion (SIC), assuming a maximum number of three common components based on the set of 14 economic variables and technical indicators, and four based on the full set of 28 predictors. Results on alternative strategies are presented in the robustness section.

Given the empirical finding that out-of-sample evidence of equity premium prediction performs worse than in-sample prediction (see for example, Bossaerts and Hillion, 1999, Goyal and Welch, 2003, 2008), our application is solely based on ex-ante identification (see Campbell, 2008). Therefore, we are interested in whether predictor variables deliver equity premium forecasts in a real-time setting and, more precisely, whether they outperform the historical average commonly used as a benchmark specification. To address the out-of-sample aspect of our analysis, the predictive regression in (1) is converted into a real-time setting, where we split the total sample into an initialization period [1:s-1] and an out-of-sample evaluation period [s:T]. More specifically, one step ahead forecasts are obtained by recursive estimates. 
Out-of-sample forecast accuracy is then assessed by the $R_{O S}^{2}$ evaluation statistic, suggested by Campbell and Thompson (2008)

$$
R_{O S}^{2}=1-\frac{\sum_{t=s}^{T}\left(r_{t}-\hat{r}_{t}\right)^{2}}{\sum_{t=s}^{T}\left(r_{t}-\bar{r}_{t}\right)^{2}}
$$

where $\left\{\hat{r}_{t}\right\}_{t=s}^{T}$ represents the out-of-sample forecasts based on the predictive variables and $\left\{\bar{r}_{t}\right\}_{t=s}^{T}$ are the forecasts using the historical average instead. Moreover, to examine whether predictors significantly contain information above and beyond the historical average, we make use of the MSFE-adjusted test statistic proposed by Clark and West (2007) to compare nested models' forecast accuracy. In detail, performance comparison is based on the null hypothesis of equal or lower mean squared forecasting errors under the benchmark specification against the one-sided alternative of lower mean squared forecasting errors using the predictive variable under analysis. Statistical inference is then assessed by an upper tail test corresponding to t-statistics obtained by regressing $\left\{d_{t}\right\}_{t=s}^{T}$ on a constant.

$$
d_{t}=\left(r_{t}-\bar{r}_{t}\right)^{2}-\left[\left(r_{t}-\hat{r}_{t, i}\right)^{2}-\left(\bar{r}_{t}-\hat{r}_{t, i}\right)^{2}\right] \quad \text { for } t=s, \ldots, T
$$

During the course of examination, we allow for various specifications to check whether empirical results are stable and economically important.

\subsection{Data description}

Our sample covers monthly observations from December 1950 through December 2014, for a total of 769 observations which should be reasonably long for our objective of stability screening. The dataset and the sample size are related to Neely et al. (2014) and updated by three additional years. Our application is based on forecasting the monthly U.S. equity premium which is defined as the difference between the continuously compounded log return of the S\&P 500 (including dividends) and the log return on a risk-free bill. We make use of 14 economic variables that have been used prevalently in the empirical literature and for comparison purposes we also focus on 14 predictive variables stemming from the category of technical trading rules. A detailed variable description is given in Appendix 1.

Economic indicators. The set of 14 economic predictor variables is a representative outline of variables commonly used to predict the equity return (see, for example, Goyal and Welch, 2008, Rapach et al., 2010). These variables comprise information about stock characteristics: (log) Dividend-price ratio (DP); (log) Dividend yield (DY); (log) Earnings- 
price ratio (EP); (log) Dividend-payout ratio (DE); Equity risk premium volatility (RVOL); Book-to-market ratio (BM) and Net equity expansion (NTIS) in addition to interest related information: Treasury bill rate (TBL); Long-term yield (LTY); Long-term Return (LTR); Term spread (TMS); Default yield spread (DFY); Default return spread (DFR) and Inflation (INFL). ${ }^{1}$

Technical indicators. Following Neely et al. (2014) the full set of 14 technical indicators is based on 3 kinds of popular technical trading strategies. At the end of each period, i.e. in our setting each month, all of these indicators provide a buy (sell) signal based on recent price movements. We generate six technical trading strategies based on movingaverage rules which compare short- (1, 2, 3 months) and long-term (9, 12 months) moving averages to detect changes in stock price trends. In addition, we obtain two technical trading strategies by comparing current with past stock prices, i.e. momentum rules. If the current price level exceeds the previous level (6, 12 months periods ago) then the trading rule generates a buy signal, i.e. a trend-following perspective. ${ }^{2}$ The third category is based on volume rules. These six technical trading indicators relate volume to price changes (shortterm=1, 2, 3 months; long-term=9, 12 months) to detect strong price trend movements, as proposed by Granville (1963). The importance of volume comes from the interpretation that price movements confirmed by high trading volume generate more serious signals of stock price trends.

Descriptive statistics. Descriptive statistics for the U.S. equity premium and predictor variables are reported in Table I. The equity premium provides on average a return of $0.52 \%$ per month with a monthly standard deviation of $4.20 \%$ which leads to an annualized Sharpe ratio of 0.43 . Summary statistics on technical indicators show a sample mean in the range of 0.68 to 0.73 which involves buy signals in at least two-third of the whole sample range. First order autocorrelation coefficients for the technical indicators are highly statistically significant and in the range of 0.60 to 0.83 . This tentatively supports the underlying assumption of technical analysis that past price trends persist into the future.

TABLE I about here

\footnotetext{
${ }^{1}$ We follow Neely et al. (2014) by using a slightly different volatility measure proposed by Mele (2007) which attenuates the outlier problem in October 1987. Because inflation information is released with a one-month delay, we follow Goyal and Welch (2008) by inserting one additional month of waiting.

${ }^{2}$ Due to a referee request we apply here a popular 6-months momentum rule, whereas Neely et al. (2014) use a 9-months momentum rule. However, the difference between the two is minor and does not affect our findings.
} 
Economic predictors on the other hand confirm previous findings of highly statistically significant persistency near the unit root for almost all variables. With the exception of the long-term return (LTR), the default return spread (DFR) and the inflation rate (INFL), all economic variables are highly autocorrelated, with $1^{\text {st }}$ order autocorrelation coefficients near 1. Second to third autocorrelation coefficients illustrate that the persistent behavior of economic variables decays comparatively slower over time relative to technical indicators.

\section{Out-of-sample equity premium prediction}

This section presents our prediction results in four steps. We start with replicating earlier exercises for a somewhat longer period (Section 3.1). Then we apply the Goyal and Welch (2003, 2008) stability procedure on the economic and technical indicators (Section 3.2) and analyze these time series with conventional break tests (Section 3.3). Finally, we apply a rolling-recursive estimation approach to measure performance stability over time (Section 3.4).

\subsection{Out-of-sample prediction results}

As a first step of our empirical analysis we document forecasting results of the 14 economic and 14 technical indicators when applying a standard recursive setting. This allows comparison with earlier studies, in particular with Neely et al. (2014) which cover a somewhat shorter period from January 1966 to December 2011. In line with the literature we start with a 15-years in-sample period and make forecast for January 1966, then increase the in-sample period by one moth and make forecasts for February 1966 etc. At the end we evaluate the average performance over these hundreds of forecast. We find that adding three additional years of observations does not qualitatively change results.

While detailed results are reported in the Appendix Table A.I, we just refer to information from the full set of economic and technical indicators by forming principal components. As expected, the $R_{O S}^{2}$ for the economic variables is negative and that for the technical indicators is positive. Nevertheless, p-values for the MSFE-adjusted test statistic are below 0.05 for economic variables, whereas technical indicators outperform the historical average just at the $10 \%$ level. $^{3}$ Principal components based on economic as well as technical

\footnotetext{
${ }^{3}$ Clark and West (2007) mentioned that the null hypothesis can be rejected even if we observe negative $R_{\text {OS }}^{2}$ due to the adjustment term which accounts for upward bias in the MSFE produced by parameter estimates that are zero under the null.
} 
indicators (Panel C) indicate highly statistical significant outperformance at the $1 \%$ level with a $R_{O S}^{2}$ of $1.30 \%$ for the full sample. Overall, this supports the notion that technical indicators contain information above and beyond economic variables over the business cycle, as shown by Neely et al. (2014).

Finally, forecasting power of nearly all predictor variables is predominantly located in recession periods, which is in line with previously reported findings motivated by Fama and French (1989), Cochrane (1999, 2007) and highlighted by Henkel et al. (2011), among others.

\subsection{Dynamic out-of-sample prediction performance}

As mentioned by Timmermann (2008) "Most of the time the forecasting models perform rather poorly, but there is evidence of relatively short-lived periods with modest return predictability” which might lead to positive $R_{O S}^{2}$ over the full sample period. This is in line with findings by Goyal and Welch (2008), who show that the predictive ability of economic variables sharply increases during the oil price shock recession in the 1970s but that the same models perform poorly if these unusual years are excluded from the sample.

To examine whether the forecast performance over the full sample (as documented in Table A.I), may benefit from short-lived periods, we follow Goyal and Welch $(2003,2008)$ in this section. They propose focusing on the cumulative sum of differences in the squared forecast errors under the benchmark specification and the squared forecast errors based on predictive variables (CDSFE).

$$
\operatorname{CDSFE}(t, i)=\sum_{t=s}^{T}\left(\left(r_{t}-\bar{r}_{t}\right)^{2}-\left(r_{t}-\hat{r}_{t, i}\right)^{2}\right)
$$

FIGURE I about here

To save space Figure I shows the out-of-sample performance of principal component indicators, relative to the benchmark, at each point in time. First, values above zero indicate a positive performance of the predictive model up to the point in time that is considered. Second, an increasing process contributes positively, whereas a declining line implies that predictive performance is negative in the period under consideration. The three panels show the predictive performance for three principal components, representing economic indicators, technical indicators and all indicators (figures for all 28 single indicators are available on request).

Overall, we confirm earlier findings: (i) We show that no prediction model outperforms the historical average consistently over time, i.e. there are no persistently upward sloping 
curves. (ii) Local predictability is concentrated in recessions rather than expansions. (iii) The indicator $\mathrm{PC}_{E c o n}$ (see Panel A) provides some outperformance up to the first half of the sample with a sharp increase in the predictive performance during the 1970s recession (as mentioned by Goyal and Welch, 2008) and around the 1980s recessions. ${ }^{4}$ (iv) None of the 14 single economic indicators performs considerably better than $\mathrm{PC}_{E c o n}$. (v) The performance of principal component predictive regressions based on technical indicators, $\mathrm{PC}_{\text {Tech }}$ (see Panel B), is never much worse than the benchmark over longer periods, i.e. there are only small negative values, and the long-term trend is rather upwards than downwards. (vi) Looking at the 14 technical indicators individually largely confirms these findings. (vii) Finally, Panel C shows forecasting performance by combining information from economic and technical indicators $\left(\mathrm{PC}_{\mathrm{All}}\right)$. The overall pattern follows $\mathrm{PC}_{E c o n}$ but is moderated by the influence of $\mathrm{PC}_{\text {Tech }}$.

Given this strong time-dependent predictive ability, further analysis seems warranted, to analyze whether predictability is solely driven by specific samples or whether predictor variables show a systematic relation. These aspects are analyzed in Sections 3.3 and 3.4.

\subsection{Structural stability tests}

Early evidence of instability in the prediction performance, using valuation ratios (see Lettau and Ludvigson, 2001, Goyal and Welch, 2003, and Ang and Bekaert, 2007 for example), has recently being linked to the presence of occasional break dates. But the possibility of occasional changes seems not to be restricted to economic variables. Park and Irwin (2007) mention that also technical trading strategies are also subject to substantial changes and their profitability tends to vanish after the late 1990's.

In Section 3.2 above, we have related the equity premium to predictor variables in a recursive estimation setting. This results in the most efficient coefficient estimates by incorporating more information as it becomes available. Nevertheless, these out-of-sample forecasts are based on the presumption, that the underlying relationship is constant or sparsely time-varying. However, recent literature (e.g., Pesaran and Timmermann, 2002, Lettau and Van Nieuwerburgh, 2008, Rapach et al., 2010, Pettenuzzo and Timmermann, 2011) highlights the effects of model and parameter instability due to occasional structural breaks. Such breaks might also explain weak out-of-sample results compared to its in-sample counterparts (see

\footnotetext{
${ }^{4}$ This finding is in line with the strong deterioration in the predictive performance of dividend-price ratios since the mid 90s, shown by Lettau and Ludvigson (2001), Goyal and Welch (2003) and Ang and Bekaert (2007) which results from a sharp increase in their persistency.
} 
Clark and McCracken, 2005). ${ }^{5}$ Rapach and Wohar (2006) and Paye and Timmermann (2006) provide evidence for the presence of structural breaks in the 1990s and highlight that the relationship between the equity premium and dividend-price ratio substantially decreased after 1990. Interest rate related variables, like the term spread, offer breakpoints in the 1970s. Accordingly, ignoring the presence of possible breaks would lead to biased estimates and thus failure to predict the equity premium out-of-sample.

Postulating one breakpoint up to time $\mathrm{T}$, the data generating process exhibits the following form

$$
\begin{array}{cc}
r_{t+1}=\alpha_{1, i}+\beta_{1, i} x_{i, t}+\varepsilon_{i, t+1} & t=1, \ldots, k_{1}, \\
r_{t+1}=\alpha_{2, i}+\beta_{2, i} x_{i, t}+\varepsilon_{i, t+1} & t=k_{1}, \ldots, T-1 .
\end{array}
$$

To examine whether structural breaks in the equity premium prediction regressions are present, we run three kinds of empirical break tests, following Rapach and Wohar (2006) and Paye and Timmermann (2006) in this respect. (1) Using in-sample predictive regressions, we employ the Andrews (1993) SupF statistic, testing the null hypothesis of no structural break against the alternative of occasional change at unknown date. We impose a 15\% trimming percentage to determine the minimum window length between breaks. ${ }^{6}$ (2) Allowing for multiple breaks, we employ the Bai and Perron (1998) UDmax and WDmax (5\%) statistics for testing the null hypothesis of no structural breaks against the alternative of multiple breaks of at most 5 occasional changes. Bai (1997) and Bai and Perron (2001) mention that the UDmax and WDmax statistics can be more powerful than Andrews SupF test in the case of multiple breaks. (3) Finally, we make use of Elliott and Müller (2006) $\widehat{q L L}$ which has good power and size properties even under heteroskedastic settings.

\section{TABLE II about here}

Results shown in Table II do not consistently provide evidence of structural instability. While empirical evidence is quite clear for technical indicators (nearly all tests do not reject the null hypothesis of no structural break), predictive regressions using economic indicators seem to be affected by breaks more intensively. Nevertheless, findings are mixed and strongly dependent on the selected break-test. Thus, neither previous evidence of structural instability

\footnotetext{
${ }^{5}$ Pesaran and Timermann (2002) and Pesaran and Timmermann (2004) show that in the presence of structural breaks, the usage of pre-break data can improve stock return predictability.

${ }^{6}$ Given general nonstationarities in the regressors, statistical inference is based on the Hansen (2000) heteroskedastic fixed-regressor bootstrap which has better size properties in finite samples.
} 
can be confirmed nor is it obvious whether and when the predictive performance might offer major instability. Therefore, to highlight possible instability, we account for possible breaks in a more dynamic estimation setting in the following section.

\subsection{Performance stability in a rolling-recursive setting}

Motivated by concerns of Clark and McCracken (2005) and Pesaran and Timmermann (2007) on possible distortions of the earlier approaches we apply here a rolling-recursive setting. This is new in the literature on equity premium prediction and complements the other approaches.

Findings presented so far are based on recursive estimates over the full sample range which might strongly benefit from the specific sample period under analysis (see Clark and McCracken, 2005). Moreover, as there is no distinct evidence of structural breaks in the empirical relationship between the equity premium and predictor variables, it is less clear whether predictive ability is stable or may solely exists at specific point in time (i.e. at the beginning or at the end of the sample). Naturally, rolling window regressions might be well suited to account for such shifts, but this approach has several disadvantages. Concerning the bias-efficiency trade-off, rolling window regressions might reduce potential estimation bias but this approach suffers from increasing estimation uncertainty (see Pesaran and Timmermann, 2007). In addition, breaks seem to be frequent and in order to account for this fact, the initialization period should be comparably short which is opposite to the requirements of the precise identification of common components.

Therefore, we account for these effects by using a rolling-recursive estimation setting where we allow the in-sample estimation period (15 years) to vary over time. In our case we shift the starting point of the out-of-sample period continuously forward by one month. Such a procedure is equal to different subsample analysis without choosing the sample start arbitrarily. In addition, we are able to examine whether the sample under analysis is responsible for obtained out-of-sample predictability results or whether the predictive ability remains even under more recent subsamples, i.e. forecasting stability over time.

In detail, Figure II shows the time-varying process of the $R_{O S}^{2}$ by starting with an estimation window over the evaluation period 1966:01-2014:12. Thus the first points of the three strategies, shown in Panels A to C, are exactly the $R_{O S}^{2}$ mentioned in Section 3.1, for example, $1.30 \%$ for $\mathrm{PC}_{\text {All }}$. Next, we examine the out-of-sample predictability over the sample 1966:02-2014:12 using an initialization period from 1951:01 to 1966:01, and so on. Thus the 
black line in Panel C shows month by month the average forecasting performance (measured

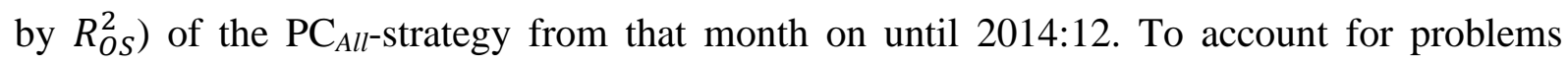
arising from small out-of-sample evaluation periods, our analysis ends concerning the evaluation period 1995:01-2014:12, i.e. covering at least 20 years. $^{7}$

FIGURE II about here

Concerning our subsample stability analysis, Figure II shows large differences between the forecast performance of economic and technical indicators through time. The time-varying $R_{O S}^{2}$ of economic predictor variables (represented by principal component predictive regressions) do not consistently outperform the benchmark model. The contrary is the case, i.e. most of the time findings reveal higher prediction errors (negative $R_{O S}^{2}$ ) in comparison to forecasts made by the historical average. Remarkably, some economic predictor variables never exceed the zero line. In contrast, technical indicators seem to be much more robust predictors over time, even though at a low level of predictability. While most technical indicators exhibit a substantial decline in the $R_{O S}^{2}$ regarding the out-of-sample evaluation period during the 1990s (as has been mentioned by Park and Irwin, 2007), the predictive performance recovers to its previous level afterwards. This relative forecasting stability of technical indicators is conferred to forecasting strategies taking economic variables and technical indicators into account.

The figure also illustrates the time-varying process of predictability during recession and expansion periods. In line with earlier presented analyses, the predictive ability of indicators consistently exhibits higher prediction errors than the historical average in expansions, but profits from recession phases.

Overall, our analysis illustrates that in contrast to the literature's focus on economic variables (motivated by Cochrane, 1999, 2007), technical indicators exhibit clearly more stability over time.

\section{Economic value of equity premium prediction}

The quality of equity premium prediction is often assessed by the returns generated by forecasting strategies, as we do in Section 3 above. However, the high instability

\footnotetext{
${ }^{7}$ As has been mentioned by Inoue and Kilian (2004) and Hansen and Timmerman (2012), out-of-sample forecast evaluation results have reduced power under short sample periods. Thus, our last evaluation period covers at least 240 months which should avoid problems arising from small sample analysis.
} 
demonstrated provides a strong motivation to examine the economic value of such strategies. In Section 4.1 we introduce into asset allocation decisions to measure the economic value of equity premium forecasts, in Section 4.2 we apply them to our data, and in Section 4.3 we examine their temporal stability.

\subsection{Asset allocation}

Statistical measures of forecast ability are informative but not necessarily decisive for investment and asset allocation decisions. Cenesizoglu and Timmermann (2012) show that statistical and economic measures of forecasting performance are only weakly positively correlated. Accordingly, low or even negative $R_{O S}^{2}$, such as the ones being documented in Section 3, may still provide economic value at the same time. In examining the economic value of forecasting indicators, we follow Marquering and Verbeek (2004), Campbell and Thompson (2008) and Neely et al. (2014) in order to keep results comparable to these studies.

We consider an investor who optimally composes his portfolio by allocating across risky assets, in our case the equity premium, and a risk-free asset according to equation (6)

$$
r_{p, s}=w_{s-1} r_{s}+r f_{s}
$$

where $r_{p, s}$ represents the portfolio return at the end of period $s$, determined by allocating a share of $w_{s-1}$ to the risky asset and 1 to the risk-free bill. For simplicity, we use simple (instead of $\log$ ) returns to conduct asset allocation exercises. We postulate a mean-variance utility function of the following form

$$
U\left(r_{p, s}\right)=E_{s-1}\left(r_{p, s}\right)-\frac{1}{2} \gamma \operatorname{Var}_{s-1}\left(r_{p, s}\right)
$$

where $\gamma$ indicates investor's degree of relative risk-aversion. Maximizing the utility function with respect to $w_{s-1}$ yields the optimal portfolio weight for the investor

$$
w_{S-1}=\left(\frac{1}{\gamma}\right)\left(\frac{E_{S-1}\left(r_{S}\right)}{\operatorname{Var}_{S-1}\left(r_{s}\right)}\right)
$$

As can be seen from equation (8), and fully in line with conventional theory, optimal portfolio allocation depends positively on the equity risk premium forecast and negatively on the conditional variance. ${ }^{8}$ Because volatility is latent and has to be approximated, we follow the

\footnotetext{
${ }^{8}$ As a referee mentions, this conventional procedure does not consider the case that high (risk-adjusted) returns may be the adequate investment for a risk-tolerant investor who "buys" risky investments and "sells" insurance to a more risk-adverse investor.
} 
recent literature (like Christiansen et al., 2012) relying on realized volatility forecasts. ${ }^{9}$ In detail, realized volatility is defined by the sum of daily squared returns in month $t$

$$
R V_{t}=\sum_{\tau=1}^{M_{t}} r_{t, \tau}^{2}
$$

where $M_{t}$ is the number of trading days and $r_{t, \tau}$ denotes the return at the day $\tau$ in month $t$. Due to the high persistency of $R V_{t}$, volatility forecasts are then obtained by using an $\mathrm{AR}(1)$ process based on the log of the realized variance which shifts the distribution closer to normality (see Christiansen et al., 2012). Using the same volatility estimate for all models does rule out differences in portfolio allocations implied by model specifications (see Figure A.I in the Appendix). We also check whether equity premium prediction models additionally add economic value due to volatility forecasts, but results are nearly unchanged (reported in the robustness section).

\subsection{The economic value of forecasting models}

To determine the economic relevance, we use different measures to examine the performance of equity premium forecasts compared to predictions based on the historical average. In addition to the average realized portfolio return and the corresponding standard deviation, we show the difference in the realized utility using predictor variables instead of the historical average (i.e. the certainty equivalent return). This utility gain can be understood as a management fee that an investor is willing to pay to have access to the information of the prediction model compared to the information of the historical average. In the following, reported values are annualized such that they can be understood as an annualized percentage management fee.

$$
\Delta C E R=\left(\left(\hat{\mu}_{i}-0.5 \gamma \hat{\sigma}_{i}^{2}\right)-\left(\hat{\mu}_{0}-0.5 \gamma \hat{\sigma}_{0}^{2}\right)\right) * 1200
$$

$\hat{\mu}_{i}\left(\hat{\sigma}_{i}^{2}\right)$ indicates the sample average (variance) of the portfolio return formed on prediction model $i$ while $\hat{\mu}_{0}\left(\hat{\sigma}_{0}^{2}\right)$ denotes the sample average (variance) using the historical average forecast instead. Additionally, we report the annualized Sharpe ratio which is defined as the portfolio excess return divided by its volatility. We follow Campbell and Thompson (2008) and Cooper and Priestley (2009) and choose a relative risk aversion coefficient of three,

\footnotetext{
${ }^{9}$ The dynamic of the stock market volatility is an important factor for asset allocation decisions. In contrast to other studies which use constant or slightly time-varying volatility measures (based on rolling window estimates of monthly historical returns) we do not regard such approaches as an appropriate way to capture the true and latent volatility process (see Andersen et al., 2003).
} 
transaction costs of 50 basis points per turnover and constrain the optimal portfolio weight for the investor by preventing short sales of stocks and taking leverage of no more than $50 \%$ (variations are reported in the robustness section). Findings are documented in Table III.

TABLE III about here

We note that average portfolio returns of forecasting strategies do not differ much from each other by relying on different conditioning variables. However, sample variances are more heterogeneous which leads to larger differences when looking at certainty equivalent returns. In comparison to results based on the MSFE, Table III shows that most predictive regressions add economic value beyond the historical average, even though the $R_{O S}^{2}$ had been very small. In the following, we focus on the annualized utility gains but findings are qualitatively the same for Sharpe ratios.

7 out of 14 economic variables outperform the historical average according to positive utility gains, while only two economic variables offer positive $R_{O S}^{2}$. However, we find large differences in realized utility gains. Three economic indicators perform comparatively well, with annualized gains above $1.80 \%$. This means that the access to information in the predictive regression forecast compared to the historical average has a value of at least 180 basis points for investors. The highest utility gain is provided by the term spread with gains of 304 basis points.

Concerning technical indicators, results are more in line with previous evidence. While the maximum utility gain is limited to 213 basis points, all forecasts by using technical indicators are valuable. Similar to the limited $R_{O S}^{2}$, the added value is smaller compared to the best economic indicators. Nevertheless, 10 technical indicators generate utility gains of more than 50 basis points and 5 out of these indicators report average gains of over 100 basis points.

Portfolio performance measures that make use of principal component predictive regressions behave well (see Neely et al., 2014). Individual principal component predictive regressions add economic value (economic variables by 241 basis points; technical indicators by 218 basis points). Even better, $\mathrm{PC}_{\text {All }}$ offers the highest Sharpe ratio (0.47) with an average utility gain of 277 basis points. 


\subsection{Stability of economic values}

Analogous to Section 3.4 we also investigate whether reported utility gains are stable over time, and whether they also exist in the more recent history. Given the time-varying nature of the $R_{O S}^{2}$ (Figure II), performance measures might face the same problems, i.e. the economic value could profit from an empirical relationship in the distant past. To account for possible instabilities, Figure III shows the annualized Sharpe ratio for a mean-variance investor with a relative risk aversion coefficient of three and allocation constraints $0 \leq$ $w_{s-1} \leq 1.5$ (transaction costs imposed). To make our results easily comparable, we use the same rolling-recursive scheme as in Section 3.4 allowing the initialization period to vary through time. For comparison purposes, this figure also shows the Sharpe ratios of using historical average forecasts and a simple buy-and-hold strategy in the S\&P 500.

\section{FIGURE III about here}

That means, for example, that the first point of the black line in Panel A provides the average Sharpe ratio for all out-of-sample forecasts made by the $\mathrm{PC}_{E c o n}$-strategy for the period between January 1966 and December 2014. The last data point covers the sample from January 1995 to December 2014, in order to have at least 20 years for calculating an average Sharpe ratio.

The resulting lines show very heterogeneous pattern across the three strategies indicated by the Sharpe ratios of investment strategies starting at different points in time. Principal component forecasts based on economic variables (Panel A) perform relatively well until the 1970s. Since then the Sharpe ratio declines and previously detected utility gains vanish, not only compared to the portfolio allocations based on the historical average forecast but also compared to a simple buy-and-hold strategy. Forecasting improvements since the late 1980s are visible but do not fully compensate the earlier decline.

A completely different path is found for technical indicators reported in Panel B. While the $R_{O S}^{2}$ is even small in magnitude, the reported Sharpe ratio indicates a tentatively increasing slope. With some exceptions, trading strategies based on $\mathrm{PC}_{T e c h}$ forecasts are more valuable than using the historical average or a simple buy-and hold strategy instead. Comparing full sample Sharpe ratios (given in Table III) with the average Sharpe ratio using our rollingrecursive estimation setting, we confirm previous findings of highly instable prediction performance concerning economic variables. While $\mathrm{PC}_{E c o n}$ yields an annualized Sharpe of 0.45 over the sample period 1966:01-2014:12, the average Sharpe ratio shrinks to 0.43 
considering our complete set of subsamples. In contrast, the average Sharpe ratio of $\mathrm{PC}_{\text {Tech }}$ is 0.55 which indicates a rise of 0.11 points compared to the evaluation sample starting in 1966:01. Again, closely related is the behavior of $\mathrm{PC}_{\text {All }}$. Reported benefits are strongly affected by the performance of technical indicators. While we observe some economic outperformance in the distant past, solely technical indicators stabilize the performance measure afterwards.

A similar behavior to that shown in Figure III is obtained if we consider utility gains measured by the annualized certainty equivalent return (Figure IV).

\section{FIGURE IV about here}

The performance of the three investment strategies improves of course when the transaction costs of 50 basis points are neglected. This case is shown for comparison purposes in the Appendix (Table A.II, Figure A.II and Figure A.III).

\section{$5 \quad$ Robustness tests}

This section briefly describes robustness exercises which are documented in length in Appendix 2 to this paper. These tests go to three directions: (1) We combine economic and technical indicators in various ways (Table A.III and Figure A.IV), (2) we demonstrate the small effect of various alternative specifications of volatility prediction models (Table A.IV and Table A.V) and (3) we examine the effect of alternative restrictions on portfolio formation, i.e. leveraged investments and shorting (Table A.VI). Our results remain qualitatively unchanged in all of these cases.

\section{Conclusions}

The issue of equity premium prediction is long standing in the literature (see Spiegel, 2008). At least for standard economic variables, Goyal and Welch (2008) have demonstrated that high predictive ability of economic indicators until the 1970s has basically disappeared thereafter. From this perspective, it seems obvious to examine the predictive ability of technical indicators and, indeed, Neely et al. (2014) show their potential. We contribute to this literature by complementing the analysis of forecasting ability by focusing on possible instability. We confirm instability of economic indicators as indicated by Goyal and Welch 
(2008), here with more data and various methods. By contrast we find much less instability of technical indicators, supporting the favorable notion by Neely et al. (2014) and even indicating economic value of technical indicator-based forecasting.

As it is our ambition to complement earlier work, we closely follow the main approach in this literature (see Goyal and Welch, 2003, 2008, Neely et al., 2014). Thus, we consider the same set of economic and technical indicators as before and basically replicate earlier results, just extending the sample period by recent years. From that point on, we apply structural stability test with a somewhat disappointing result as various tests do not converge on the breakpoints. However, there seem to be breakpoints and this motivates us to complement the standard recursive approach in demonstrating forecasting performance over time by a specific rolling-recursive approach.

We aim for simulating the fact that investors may enter the market at an ex ante unknown point of time and that they do not use infinite information from the past due to possible instability (which is real as we have shown). Thus, we propose a 15 years long insample estimation period and forecast the equity premium from that point on until the last month of our sample, i.e. December 2014. Accordingly, an investor may have invested at any month since January 1966 until January 1995 (in order to ensure a long out-of-sample period). We find from this rolling-recursive approach that indeed a strategy which had followed economic indicators would perform very instable over time, but strategies built on technical indicators do much less.

Thus, we examine the possible economic value of such forecasting indicators. Largely confirming earlier findings, economic indicators do not provide economic value in a consistent way. By contrast, however, technical indicators consistently deliver economic value. This value tends to increase over time - which is in stark contrast to economic indicators - and it is higher than the economic value of benchmark investment strategies over almost all sub-samples. Providing a single figure on the predictive ability of technical indicators, their average annualized Sharpe ratio (over the rolling-recursive estimations) is about 0.55 (after transaction costs) and thus provides sizeable utility gains of 152 (105) basis points on average compared to a strategy based on the historical mean (buy and hold).

Overall, predictive ability of economic and technical indicators seems to be of similar quality when assessed by their forecasting errors in the long-term. However, performance over time is completely different: economic indicators lose power but technical indicators remain powerful or even increase in predictive power. Thus technical indicators perform more 
consistently over time. When we complement statistical performance with measures of economic value, which should be more important for the functioning of financial markets, the discrepancy between economic and technical indicators widens further. Only technical indicators provide economic values and they do this in a quite stable way. This may motivate further research in understanding the robustness of our finding and its origins. 


\section{References}

Andersen, T.G., T. Bollerslev, F.X. Diebold, and P. Labys (2003), Modeling and Forecasting Realized Volatility, Econometrica 71 (2), 529-626.

Andrews, D.W.K. (1993), Tests for Parameter Instability and Structural Change with Unknown Change Point, Econometrica 61 (4), 821-856.

Ang, A., and G. Bekaert (2007), Stock Return Predictability: Is it There? Review of Financial Studies 20 (3), 651-707.

Bai, J. (1997), Estimation of a Change Point in Multiple Regressions, Review of Economics and Statistics 79 (4), 551-563.

Bai, J., and P. Perron (1998), Estimating and Testing Linear Models With Multiple Structural Changes, Econometrica 66 (1), 47-78.

Bai, J., and P. Perron (2006), Multiple Structural Change Models: A Simulation Analysis, in P.C.B. Phillips, D. Corbae, S. Durlauf, and B.E. Hansen, eds.: Econometric Theory and Practice: Frontiers of Analysis and Applied Research, Cambridge University Press, New York.

Bossaerts, P., and P. Hillion (1999), Implementing Statistical Criteria to Select Return Forecasting Models: What Do We Learn? Review of Financial Studies 12 (2), 405-428.

Brock, W., J. Lakonishok, and B. LeBaron (1992), Simple Technical Trading Rules and the Stochastic Properties of Stock Returns, Journal of Finance 47 (5), 1731-1764.

Brown, S.J., W.N. Goetzmann, and A. Kumar (1998), The Dow Theory: William Peter Hamilton's Track Record Reconsidered, Journal of Finance 53 (4), 1311-1333.

Campbell, J.Y. (2008), Viewpoint: Estimating the Equity Premium, Canadian Journal of Economics 41 (1), 1-21.

Campbell, J.Y., and R.J. Shiller (1988a), The Dividend-Price Ratio and Expectations of Future Dividends and Discount Factors, Review of Financial Studies 1 (3), 195-228.

Campbell, J.Y., and R.J. Shiller (1988b), Stock Prices, Earnings, and Expected Dividends, Journal of Finance 43 (3), 661-676.

Campbell, J.Y., and S.B. Thompson (2008), Predicting Excess Stock Returns Out of Sample: Can Anything Beat the Historical Average? Review of Financial Studies 21 (4), 15091531.

Cenesizoglu, T., and A. Timmermann (2012), Do Return Prediction Models Add Economic Value? Journal of Banking and Finance 36 (11), 2974-2987.

Christiansen, C., M. Schmeling, and A. Schrimpf (2012), A Comprehensive Look at Financial Volatility Prediction by Economic Variables, Journal of Applied Econometrics 27 (6), 956-977.

Clarke, T.E., and M.W. McCracken (2005), The Power of Tests of Predictive Ability in the Presence of Structural Breaks, Journal of Econometrics 124 (1), 1-31.

Clark, T.E., and K.D. West (2007), Approximately Normal Test for Equal Predictive Accuracy in Nested Models, Journal of Econometrics 138 (1), 291-311.

Cochrane, J.H. (1999), New Facts in Finance, Federal Reserve Bank of Chicago Economic Perspectives 23 (3), 36-58.

Cochrane, J.H. (2007), Financial Markets and the Real Economy, in R. Mehra, eds.: Handbook of Equity Premium, Elsevier, Amsterdam.

Cochrane, J.H. (2008), The Dog That Did Not Bark: A Defense of Return Predictability, Review of Financial Studies 21 (4), 1533-1575.

Cooper, I. and R. Priestley (2009), Time-Varying Risk Premiums and the Output Gap, Review of Financial Studies 22 (7), 2801-2833.

Elliott, G., and U.K. Müller (2006), Efficient Tests for General Persistent Time Variation in Regression Coefficients, Review of Economic Studies 73 (4), 907-940. 
Fama, E.F., and K.R. French (1988), Dividend Yields and Expected Stock Returns, Journal of Financial Economics 22 (1), 3-25.

Fama, E.F., and K.R. French (1989), Business Conditions and Expected Returns on Stocks and Bonds, Journal of Financial Economics 25 (1), 23-49.

Goyal, A., and I. Welch (2003), Predicting the Equity Premium with Dividend Ratios, Management Science 49 (5), 639-654.

Goyal, A., and I. Welch (2008), A Comprehensive Look at the Empirical Performance of Equity Premium Prediction, Review of Financial Studies 21 (4), 1455-1508.

Granville, J. (1963), Granville's New Key to Stock Market Profits, Prentice-Hall, New York.

Hansen, B.E. (2000), Testing for Structural Change in Conditional Models, Journal of Econometrics 97 (1), 93-115.

Hansen, P.R., and A. Timmermann (2012), Choice of Sample Split in Out-of-Sample Forecast Evaluation, European University Institute Working Paper ECO 2012/10.

Henkel, S.J., J.S. Martin, and F. Nardari (2011), Time-Varying Short-Horizon Predictability, Journal of Financial Economics 99 (3), 560-580.

Inoue, A., and L. Kilian (2004), In-sample or Out-of-Sample Tests of Predictability: Which One Should We Use? Econometric Reviews 23 (4), 371-402.

Ledoit, O., and M. Wolf (2008), Robust Performance Hypothesis Testing with the Sharpe Ratio, Journal of Empirical Finance 15 (5), 850-859.

Lettau, M., and S. Ludvigson (2001), Consumption, Aggregate Wealth, and Expected Stock Returns, Journal of Finance 56 (3), 815-849.

Lettau M., and S. Van Nieuwerburgh (2008), Reconciling the Return Predictability Evidence, Review of Financial Studies 21 (4), 1607-1652.

Lo, A.W., H. Mamaysky, and J. Wang (2000), Foundations of Technical Analysis: Computational Algorithms, Statistical Inference, and Empirical Implementation, Journal of Finance 55 (4), 1705-1765.

Marquering, W., and M. Verbeek (2004), The Economic Value of Predicting Stock Index Returns and Volatility, Journal of Financial and Quantitative Analysis 39 (2), 407-429.

Mele, A. (2007), Asymmetric Stock Market Volatility and the Cyclical Behavior of Expected Returns, Journal of Financial Economics 86 (2), 446-478.

Neely, C.J., D. Rapach, J. Tu, and G. Zhou (2014), Forecasting the Equity Risk Premium: The Role of Technical Indicators, Management Science 60 (7), 1772-1791.

Park, C.H., and S.H. Irwin (2007), What Do We Know about the Profitability of Technical Analysis? Journal of Economic Surveys 21 (4), 786-826.

Paye, B.S., and A. Timmermann (2006), Instability of Return Prediction Models, Journal of Empirical Finance 13 (3), 274-315.

Pesaran, M.H., and A. Timmermann (2002), Market Timing and Return Prediction under Model Instability, Journal of Empirical Finance 9 (5), 495-510.

Pesaran, M.H., and A. Timmermann (2004), How Costly Is it to Ignore Breaks when Forecasting the Direction of a Time Series? International Journal of Forecasting 20 (3), 411-425.

Pesaran, M.H., and A. Timmermann (2007), Selection of Estimation Window in the Presence of Breaks, Journal of Econometrics 137 (1), 134-161.

Pettenuzzo, D., and A. Timmermann (2011), Predictability of Stock Returns and Asset Allocation under Structural Breaks, Journal of Econometrics 164 (1), 60-78.

Politis, D.N., and J.P. Romano (1992), A Circular Block-resampling Procedure for Stationary Data, in R. LePage and L. Billard, eds.: Exploring the Limits of Bootstrap, Wiley, New York.

Rapach, D.E., and M.E. Wohar (2006), Structural Breaks and Predictive Regression Models of Aggregate U.S. Stock Returns, Journal of Financial Econometrics 4 (2), 238-274. 
Rapach, D.E., J.K. Strauss, and G. Zhou (2010), Out-of-Sample Equity Premium Prediction: Combination Forecasts and Links to the Real Economy, Review of Financial Studies 23 (2), 821-862.

Rapach, D.E., and G. Zhou (2013), Forecasting Stock Returns, in G. Elliott and A. Timmermann, eds.: Handbook of Economic Forecasting, Volume 2, Elsevier, Amsterdam.

Spiegel, M. (2008), Forecasting the Equity Premium: Where We Stand Today, Review of Financial Studies 21 (4), 1453-1454.

Stock, J.H., and M.W. Watson (2002a), Macroeconomic Forecasting Using Diffusion Indexes, Journal of Business and Economic Statistics 20 (2), 147-162.

Stock, J.H., and M.W. Watson (2002b), Forecasting Using Principal Components From a Large Number of Predictors, Journal of the American Statistical Association 97 (460), 1167-1179.

Timmermann, A. (2008), Elusive Return Predictability, International Journal of Forecasting, 24 (1), 1-18.

Zhu, X., and J. Zhu (2013), Predicting Stock Returns: A Regime-Switching Combination Approach and Economic Links, Journal of Banking and Finance 37 (11), 4120-4133. 
Table I. Summary statistics

\begin{tabular}{|c|c|c|c|c|c|c|c|c|}
\hline Variable & Mean & Std. & Skew. & Kurt. & $\mathrm{AC}(1)$ & $\mathrm{AC}(2)$ & $\mathrm{AC}(3)$ & $\begin{array}{c}\text { Sharpe } \\
\text { ratio }\end{array}$ \\
\hline$r_{t}$ & 0.52 & 4.20 & -0.67 & 5.42 & 0.06 & -0.03 & 0.04 & 0.43 \\
\hline \multicolumn{9}{|c|}{ Economic variables } \\
\hline DP & -3.51 & 0.42 & -0.31 & 2.47 & 0.99 & 0.98 & 0.97 & \\
\hline DY & -3.50 & 0.42 & -0.31 & 2.49 & 0.99 & 0.98 & 0.97 & \\
\hline EP & -2.78 & 0.43 & -0.85 & 6.09 & 0.99 & 0.97 & 0.94 & \\
\hline $\mathrm{DE}$ & -0.73 & 0.30 & 2.54 & 18.06 & 0.99 & 0.95 & 0.90 & \\
\hline RVOL & 0.14 & 0.05 & 0.81 & 3.88 & 0.96 & 0.92 & 0.88 & \\
\hline BM & 0.53 & 0.25 & 0.52 & 2.60 & 0.99 & 0.99 & 0.98 & \\
\hline NTIS & 0.01 & 0.02 & -1.08 & 4.46 & 0.98 & 0.95 & 0.92 & \\
\hline TBL & 4.46 & 3.05 & 0.88 & 4.20 & 0.99 & 0.97 & 0.95 & \\
\hline LTY & 6.15 & 2.72 & 0.83 & 3.22 & 0.99 & 0.98 & 0.98 & \\
\hline LTR & 0.55 & 2.75 & 0.51 & 6.33 & 0.04 & -0.07 & -0.02 & \\
\hline TMS & 1.69 & 1.42 & -0.11 & 2.81 & 0.96 & 0.91 & 0.86 & \\
\hline DFY & 0.96 & 0.45 & 1.81 & 7.54 & 0.97 & 0.92 & 0.88 & \\
\hline DFR & 0.02 & 1.38 & -0.34 & 10.00 & -0.09 & -0.06 & -0.02 & \\
\hline INFL & 0.30 & 0.33 & 0.55 & 7.29 & 0.61 & 0.47 & 0.38 & \\
\hline \multicolumn{9}{|c|}{ Technical indicators } \\
\hline $\operatorname{MA}(1,9)$ & 0.69 & 0.46 & -0.82 & 1.68 & 0.70 & 0.55 & 0.43 & \\
\hline $\mathrm{MA}(1,12)$ & 0.72 & 0.45 & -0.96 & 1.92 & 0.78 & 0.65 & 0.53 & \\
\hline $\operatorname{MA}(2,9)$ & 0.70 & 0.46 & -0.85 & 1.72 & 0.77 & 0.60 & 0.47 & \\
\hline $\operatorname{MA}(2,12)$ & 0.72 & 0.45 & -0.95 & 1.91 & 0.83 & 0.69 & 0.56 & \\
\hline MA(3,9) & 0.70 & 0.46 & -0.88 & 1.77 & 0.79 & 0.62 & 0.48 & \\
\hline $\mathrm{MA}(3,12)$ & 0.72 & 0.45 & -0.98 & 1.95 & 0.83 & 0.68 & 0.57 & \\
\hline $\operatorname{MOM}(6)$ & 0.69 & 0.46 & -0.82 & 1.67 & 0.69 & 0.55 & 0.44 & \\
\hline $\operatorname{MOM}(12)$ & 0.73 & 0.44 & -1.05 & 2.10 & 0.81 & 0.72 & 0.64 & \\
\hline $\operatorname{VOL}(1,9)$ & 0.68 & 0.47 & -0.77 & 1.60 & 0.60 & 0.54 & 0.42 & \\
\hline $\operatorname{VOL}(1,12)$ & 0.71 & 0.46 & -0.90 & 1.82 & 0.70 & 0.64 & 0.50 & \\
\hline $\operatorname{VOL}(2,9)$ & 0.68 & 0.47 & -0.75 & 1.57 & 0.76 & 0.56 & 0.46 & \\
\hline $\operatorname{VOL}(2,12)$ & 0.70 & 0.46 & -0.88 & 1.77 & 0.82 & 0.65 & 0.56 & \\
\hline $\operatorname{VOL}(3,9)$ & 0.69 & 0.46 & -0.84 & 1.70 & 0.76 & 0.58 & 0.45 & \\
\hline $\operatorname{VOL}(3,12)$ & 0.70 & 0.46 & -0.88 & 1.78 & 0.83 & 0.70 & 0.58 & \\
\hline
\end{tabular}

Notes: The table reports summary statistics, including mean, standard deviation (Std.), Skewness (Skew.) and Kurtosis (Kurt.) of the monthly log equity premium (in percent) and predictor variables stemming from economic and technical indicators. We also report the first to third-order autocorrelation coefficient AC(.) and the annualized Sharpe ratio for the log equity premium. The sample period is December 1950 to December 2014. A full description of the data is given in the Data Appendix. 
Figure I: Dynamic predictive performance at any point of time

Panel A: $\mathrm{PC}_{\text {Econ }}$

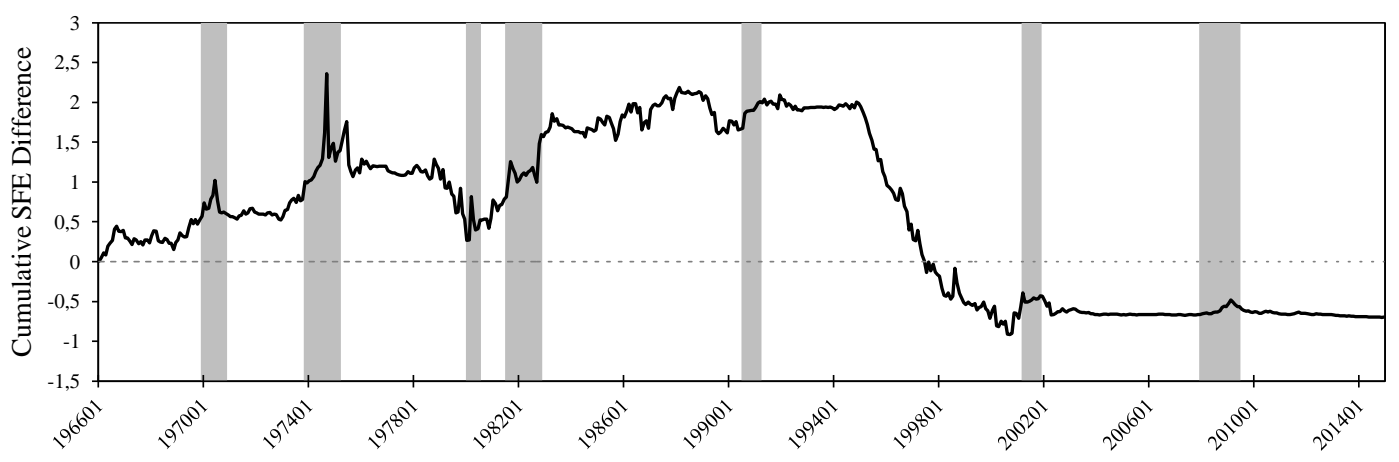

Panel B: $\mathrm{PC}_{\text {Tech }}$

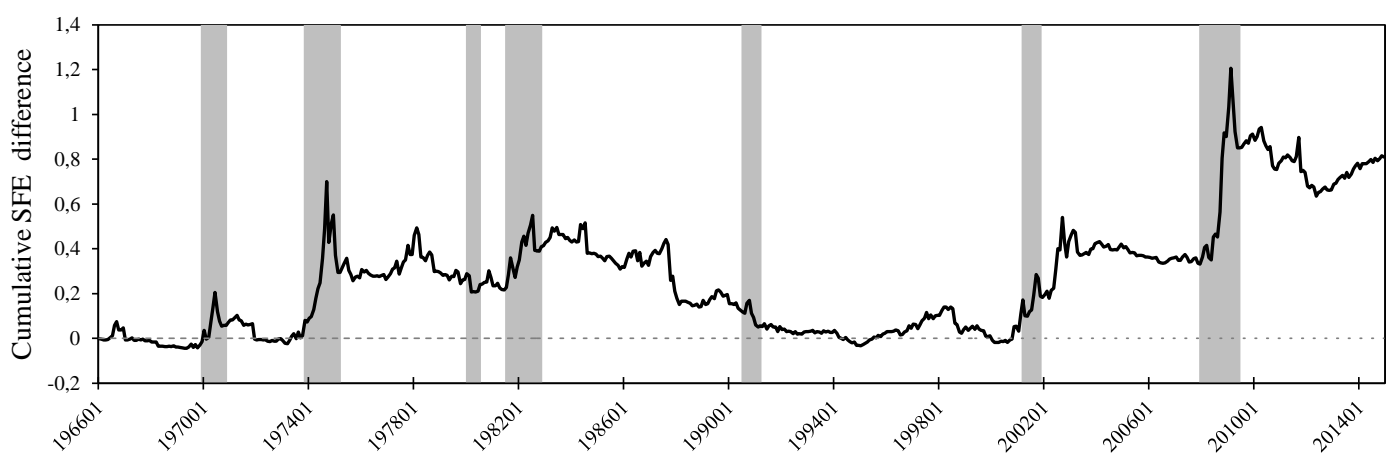

Panel C: $\mathrm{PC}_{\text {All }}$

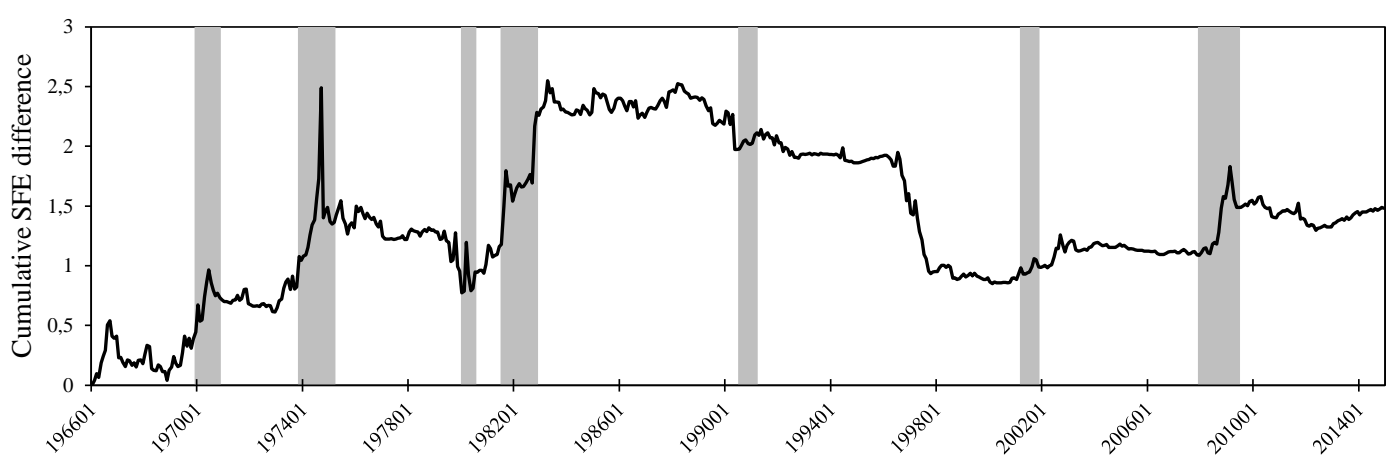

Notes: The figures plots the dynamic out-of-sample predictive performance of forecasts based principal component from the full set of macroeconomic variables $\left(\mathrm{PC}_{E c o n}\right)$ and technical indicators $\left(\mathrm{PC}_{T e c h}\right)$ as well as taking both predictor groups simultaneously into account $\left(\mathrm{PC}_{\text {All }}\right)$. Following Goyal and Welch (2003, 2008), the graphs show the cumulative sum of differences in the squared prediction errors under the benchmark specification and the squared prediction errors based on information regarding predictive variables: $\operatorname{CDSFE}(t, i)=\sum_{t=s}^{T}\left(\left(r_{t}-\bar{r}_{t}\right)^{2}-\left(r_{t}-\hat{r}_{t, i}\right)^{2}\right)$ where $\left(r_{t}-\bar{r}_{t}\right)^{2}$ are squared prediction errors of the historical average and $\left(r_{t}-\hat{r}_{t, i}\right)^{2}$ are the forecasting errors of model $i$ named in the headings. Shaded areas respond to NBER dated recessions. Overall, upward sloping curves characterize lower MSPE by making use of predictor variables. 
Table II. Equity premium predictive regression and structural break tests

\begin{tabular}{|c|c|c|c|c|c|c|c|c|c|c|c|}
\hline Predictor & SupF & Breakpoint & UDmax & WDmax (5\%) & $\widehat{q L L}$ & Predictor & SupF & Breakpoint & UDmax & WDmax (5\%) & $\widehat{q L L}$ \\
\hline \multicolumn{12}{|c|}{$\underline{\text { Panel A: Bivariate predictive regression forecasts }}$} \\
\hline DP & 10.00 & 1994:10 & 9.72 & $13.38^{\dagger}$ & -10.95 & $\mathrm{MA}(1,9)$ & 7.75 & 2000:08 & 9.36 & 11.32 & -10.42 \\
\hline DY & 11.57 & 1994:10 & $11.21^{*}$ & $14.03^{\dagger}$ & -11.23 & $\mathrm{MA}(1,12)$ & 3.93 & 1998:09 & 6.88 & 8.72 & -7.53 \\
\hline $\mathrm{EP}$ & 3.76 & 1982:06 & $11.85^{* *}$ & $15.00^{\dagger}$ & -10.33 & $\operatorname{MA}(2,9)$ & 4.30 & 2000:09 & 6.59 & 10.00 & -7.08 \\
\hline $\mathrm{DE}$ & $14.47 * *$ & 1974:08 & $18.35^{* * *}$ & $18.35^{\dagger}$ & -7.59 & $\operatorname{MA}(2,12)$ & 3.36 & $1961: 10$ & 4.57 & 6.85 & -6.79 \\
\hline RVOL & 4.89 & $1961: 10$ & 7.01 & 8.25 & -11.06 & MA(3,9) & 3.24 & $1961: 10$ & 5.84 & 8.11 & -7.49 \\
\hline $\mathrm{BM}$ & 6.58 & 1969:03 & $10.64 *$ & $12.87^{\dagger}$ & -9.83 & $\operatorname{MA}(3,12)$ & 3.56 & $1961: 10$ & 5.36 & 7.88 & -7.88 \\
\hline NTIS & 9.89 & 2003:02 & $10.86 *$ & $13.13^{\dagger}$ & $-16.66^{* *}$ & $\operatorname{MOM}(6)$ & 6.98 & 2000:01 & $10.28 *$ & 12.23 & -9.69 \\
\hline TBL & $19.07 * * *$ & 1974:08 & $23.74^{* * *}$ & $23.74^{\dagger}$ & -10.16 & $\operatorname{MOM}(12)$ & 3.83 & $1961: 10$ & 5.88 & 8.06 & -7.40 \\
\hline LTY & $16.33^{* *}$ & 1974:08 & $20.53 * * *$ & $20.53^{\dagger}$ & -8.89 & VOL $(1,9)$ & 4.25 & $1961: 10$ & 5.77 & 7.93 & -6.40 \\
\hline LTR & 4.84 & 1961:10 & 6.71 & 7.21 & -8.67 & $\operatorname{VOL}(1,12)$ & 4.95 & 1964:06 & 6.75 & 9.27 & -7.35 \\
\hline TMS & $12.15^{* *}$ & 1975:05 & $14.13^{* *}$ & $14.13^{\dagger}$ & -11.94 & $\operatorname{VOL}(2,9)$ & 8.42 & 1969:04 & $10.51 *$ & 10.79 & -8.70 \\
\hline DFY & 4.61 & $1961: 10$ & $11.19 *$ & $13.17^{\dagger}$ & $-13.49 *$ & $\operatorname{VOL}(2,12)$ & 7.82 & 1965:09 & 10.15 & 11.35 & -9.38 \\
\hline DFR & 9.42 & 1973:01 & $11.22 *$ & 11.22 & -8.77 & VOL $(3,9)$ & 4.66 & 2000:01 & $10.83 *$ & $13.88^{\dagger}$ & -8.84 \\
\hline INFL & 7.94 & 1974:08 & 9.88 & 11.62 & -9.42 & $\operatorname{VOL}(3,12)$ & 5.01 & 2000:01 & 7.79 & 10.48 & -8.52 \\
\hline \multicolumn{12}{|c|}{$\underline{\text { Panel B: Principal component predictive regression forecasts }}$} \\
\hline $\mathrm{PC}_{E c o n}\left(1^{\mathrm{st}}\right)$ & 6.97 & 1982:06 & $10.66 *$ & 12.54 & -9.61 & $\mathrm{PC}_{\text {Tech }}\left(1^{\mathrm{st}}\right)$ & 4.30 & 2000:02 & 7.59 & 9.75 & -7.15 \\
\hline $\mathrm{PC}_{\text {Econ }}\left(1^{\text {st }}-2^{\text {nd }}\right)$ & 10.28 & 1994:11 & $14.50 * *$ & $17.68^{\dagger}$ & $-19.93^{* *}$ & $\mathrm{PC}_{\text {Tech }}\left(1^{\mathrm{st}}-2^{\mathrm{nd}}\right)$ & 6.54 & 1965:03 & 8.81 & 11.85 & -12.41 \\
\hline $\mathrm{PC}_{E c o n}\left(1^{\mathrm{st}}-3^{\text {rd }}\right)$ & $31.10 * * *$ & 1994:11 & $30.07 * * *$ & $30.07^{\dagger}$ & -21.44 & $\mathrm{PC}_{\text {Tech }}\left(1^{\mathrm{st}}-3^{\mathrm{rd}}\right)$ & 7.09 & $1965: 03$ & 9.30 & 12.37 & -15.17 \\
\hline \multicolumn{12}{|c|}{$\underline{\text { Panel C: Principal component predictive regression forecasts, all predictors }}$} \\
\hline $\mathrm{PC}_{\text {All }}\left(1^{\mathrm{st}}\right)$ & 4.52 & 2000:02 & 7.27 & 9.57 & -6.85 & & & & & & \\
\hline $\mathrm{PC}_{\text {All }}\left(1^{\mathrm{st}}-2^{\mathrm{nd}}\right)$ & 5.45 & 1994:10 & 9.06 & 12.87 & -10.00 & & & & & & \\
\hline $\mathrm{PC}_{\text {All }}\left(1^{\mathrm{st}}-3^{\mathrm{rd}}\right)$ & 11.50 & 1994:11 & $14.62 * *$ & $19.31^{\dagger}$ & -18.71 & & & & & & \\
\hline $\mathrm{PC}_{\text {All }}\left(1^{\mathrm{st}}-4^{\mathrm{th}}\right)$ & $21.86 *$ & 1994:11 & $21.33 * * *$ & $21.33^{\dagger}$ & -18.37 & & & & & & \\
\hline
\end{tabular}

Notes: This table reports several test statistics to analyze whether an occasional change exists over the sample period 1950:12-2014:12. We employ Andrews (1993) SupF statistic and estimated breakpoints with stars refer to significance levels of $10 \%(*), 5 \%(* *)$, and $1 \%(* * *)$ based the heteroskedastic fixed-regressor bootstrap proposed by Hansen (2000). SupF statistic tests the null hypothesis of no structural break against the one-sided alternative that a structural change exists. We also account for multiple breaks (following Bai and Perron, 1998) by testing the null hypothesis of zero breaks against the alternative of at most 5 breaks. $10 \%$, $5 \%$, and $1 \%$ critical values equal 10.16 , 11.70, 15.41 for UDmax (stars refer to significance at corresponding levels) and the $5 \%$ critical value for WDmax equals 12.81 ; significance is indicated by ${ }^{\dagger}$. In addition, $\widehat{q L L}$ indicates the tests statistic proposed by Elliot and Müller (2006) with stars refer to significance levels of $10 \%(*)$, 5\% (**), and $1 \%(* * *)$. 
Figure II: Time-varying predictive performance

Panel A: $\mathrm{PC}_{\text {Econ }}$

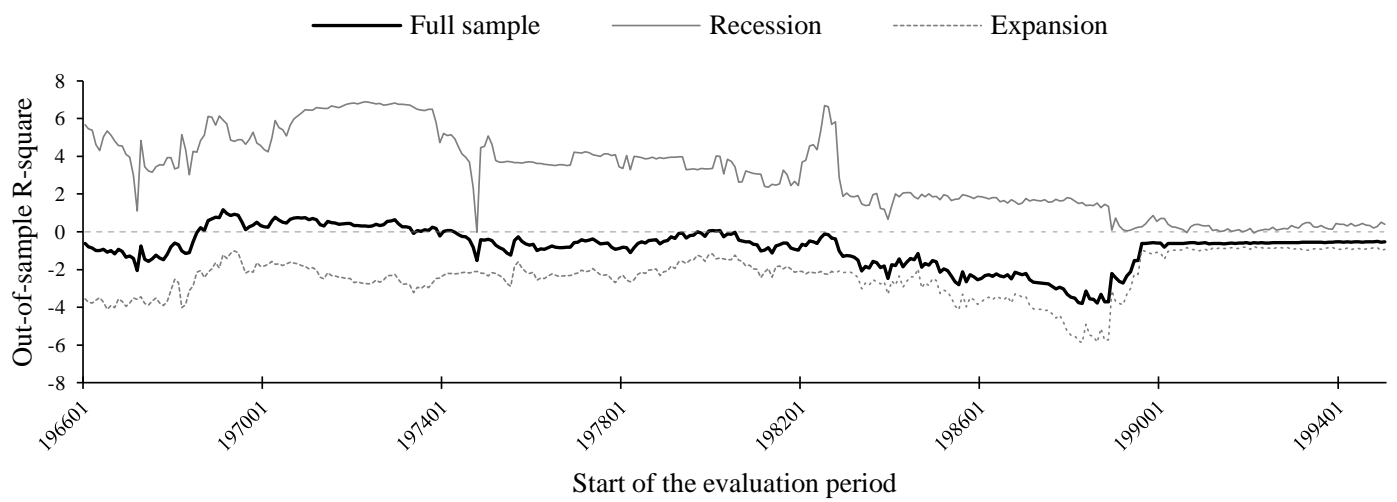

Panel B: $\mathrm{PC}_{\text {Tech }}$

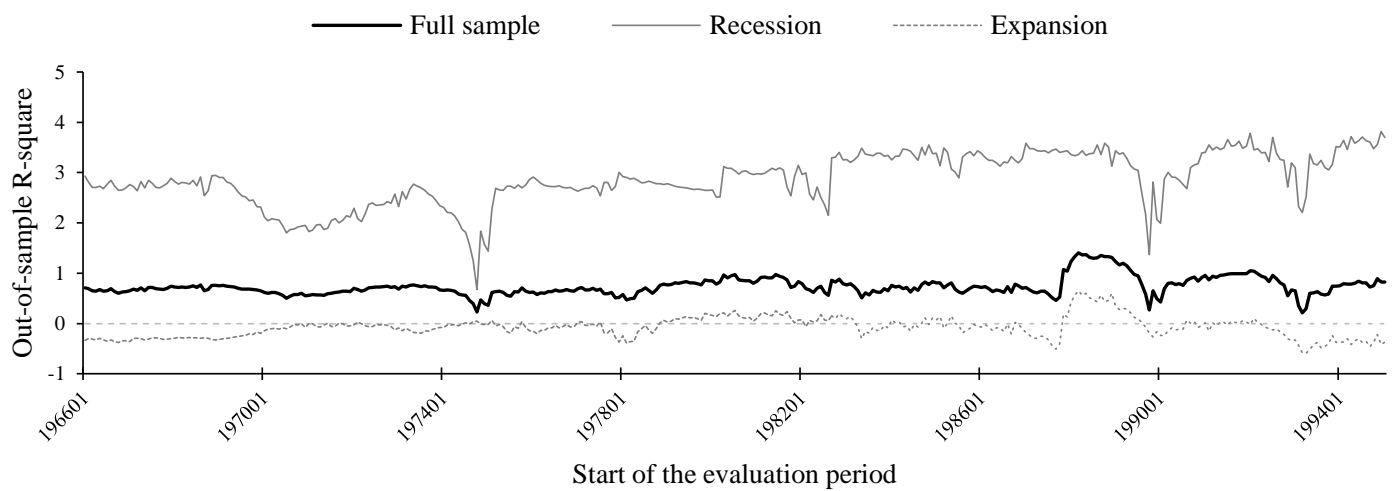

Panel C: $\mathrm{PC}_{\text {All }}$

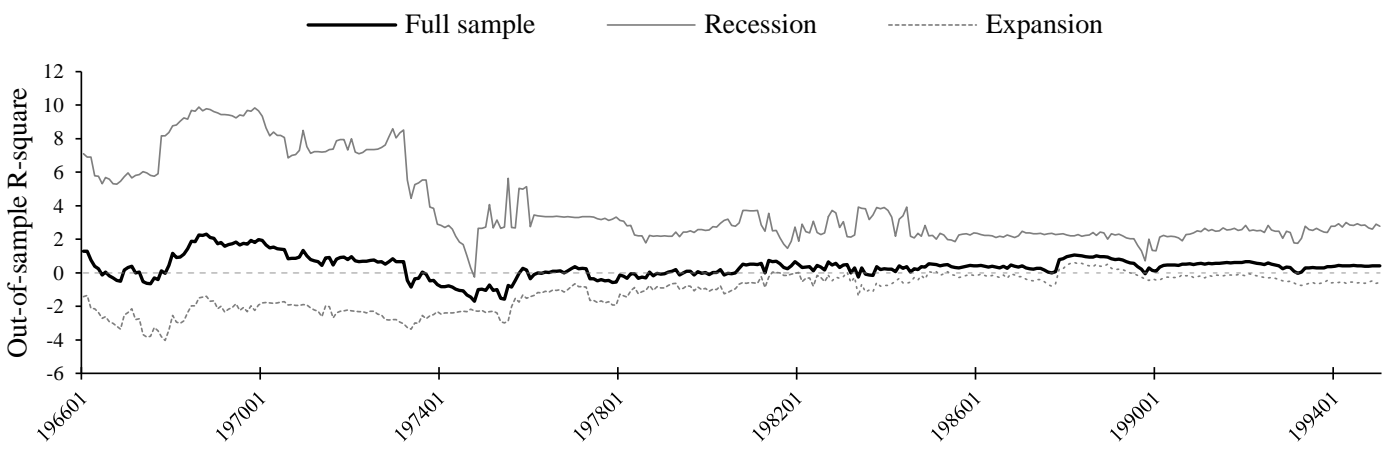

Start of the evaluation period

Notes: These figures show the time-varying out-of-sample predictive performance measured by the $R_{O S}^{2}$, over different subsamples. Our analysis starts with recursive forecast estimation over an initial in-sample estimation period of 15 years (1950:12-1965:12) and conduct real-time forecasts up to 2014:12. Next we discard the most distant data (i.e. 1950:12), yielding an in-sample estimation sample 1951:01-1966:01 (15 years) and perform out-ofsample forecasts up to 2014:12, the most recent data of our sample period. The beginning of the out-of-sample evaluation period is given on the x-axis. Thus the last $R_{O S}^{2}$ is obtained over the sample period 1995:01-2014:12. The black line shows the time-varying $R_{O S}^{2}$, the grey solid line signals the $R_{O S}^{2}$ regarding recessions and the grey dotted line corresponds to the $R_{O S}^{2}$ over expansions. Corresponding predictive regressions are named in the headings. 
Table III. Economic measures of forecasting performance, (transaction costs $=50 \mathrm{bp}$ )

\begin{tabular}{lccccccccc}
\hline Predictor & Mean & Std. & $\begin{array}{c}\Delta \text { CER } \\
\text { (ann.) }\end{array}$ & SR & Predictor & Mean & Std. & $\begin{array}{c}\Delta \text { CER } \\
\text { (ann.) }\end{array}$ & SR \\
\hline HA & $0.92 \%$ & 5.34 & $5.96 \%$ & 0.32 & & & & &
\end{tabular}

Panel A: Bivariate predictive regression forecasts

\begin{tabular}{|c|c|c|c|c|c|c|c|c|c|}
\hline DP & $0.72 \%$ & 4.29 & $-0.64 \%$ & 0.24 & MA(1,9) & $0.89 \%$ & 4.93 & $0.40 \%$ & 0.33 \\
\hline DY & $0.68 \%$ & 4.22 & $-1.03 \%$ & 0.21 & $\operatorname{MA}(1,12)$ & $1.02 \%$ & 4.98 & $1.84 \%$ & 0.42 \\
\hline EP & $0.92 \%$ & 5.00 & $0.51 \%$ & 0.34 & $\operatorname{MA}(2,9)$ & $0.92 \%$ & 4.97 & $0.65 \%$ & 0.35 \\
\hline $\mathrm{DE}$ & $0.77 \%$ & 4.31 & $-0.03 \%$ & 0.28 & $\operatorname{MA}(2,12)$ & $1.04 \%$ & 4.96 & $2.13 \%$ & $0.43^{*}$ \\
\hline RVOL & $0.96 \%$ & 5.55 & $0.03 \%$ & 0.34 & $\mathrm{MA}(3,9)$ & $0.97 \%$ & 4.87 & $1.43 \%$ & 0.39 \\
\hline BM & $0.85 \%$ & 5.14 & $-0.54 \%$ & 0.29 & $\operatorname{MA}(3,12)$ & $0.93 \%$ & 5.06 & $0.56 \%$ & 0.34 \\
\hline NTIS & $0.92 \%$ & 5.40 & $-0.15 \%$ & 0.32 & $\operatorname{MOM}(6)$ & $0.87 \%$ & 4.97 & $0.02 \%$ & 0.31 \\
\hline TBL & $0.90 \%$ & 3.97 & $2.04 \%$ & 0.42 & MOM(12) & $0.94 \%$ & 5.17 & $0.46 \%$ & 0.34 \\
\hline LTY & $0.86 \%$ & 3.69 & $1.89 \%$ & 0.41 & $\operatorname{VOL}(1,9)$ & $0.92 \%$ & 5.06 & $0.51 \%$ & 0.34 \\
\hline LTR & $0.83 \%$ & 4.98 & $-0.43 \%$ & 0.29 & $\operatorname{VOL}(1,12)$ & $0.98 \%$ & 4.91 & $1.48 \%$ & 0.39 \\
\hline TMS & $1.13 \%$ & 5.04 & $3.04 \%$ & $0.49 * *$ & $\operatorname{VOL}(2,9)$ & $0.97 \%$ & 5.16 & $0.88 \%$ & 0.37 \\
\hline DFY & $0.95 \%$ & 5.47 & $0.06 \%$ & 0.33 & $\operatorname{VOL}(2,12)$ & $0.96 \%$ & 5.12 & $0.80 \%$ & 0.36 \\
\hline DFR & $0.85 \%$ & 5.22 & $-0.68 \%$ & 0.28 & $\operatorname{VOL}(3,9)$ & $0.90 \%$ & 5.08 & $0.19 \%$ & 0.32 \\
\hline INFL & $0.88 \%$ & 4.84 & $0.37 \%$ & 0.33 & $\operatorname{VOL}(3,12)$ & $0.97 \%$ & 4.98 & $1.17 \%$ & 0.38 \\
\hline & & & tive & & & & & & \\
\hline $\mathrm{PC}_{\text {Econ }}$ & $0.92 \%$ & 3.89 & $2.41 \%$ & 0.45 & $\mathrm{PC}_{\text {Tech }}$ & $1.06 \%$ & 5.01 & $2.18 \%$ & $0.44^{*}$ \\
\hline
\end{tabular}

Panel C: Principal component predictive regression forecasts, all predictors

$\begin{array}{lllll}\mathrm{PC}_{\text {All }} & 1.02 \% & 4.42 & 2.77 \% & 0.47 *\end{array}$

Notes: The Table reports means and standard deviations (Std.) of portfolio returns for a mean-variance investor with relative risk aversion coefficient of three and transaction costs of 50 basis points per monthly turnover over the evaluation period 1966:01-2014:12. $\triangle$ CER denotes the annualized certainty equivalent return gain of predictive regression forecasts in comparison to the historical average forecast and SR is the annualized Sharpe ratio defined as the average portfolio excess return divided by the sample standard deviation. Conditional variance forecasts are obtained by an AR(1) process of stock returns realized volatility. HA indicates the historical average forecast where portfolio performance measures are given in levels, Panel A reveals results for bivariate predictive models; Panel B shows results using principal component extracted from the full set of macroeconomic variables $\left(\mathrm{PC}_{E c o n}\right)$ and technical indicators $\left(\mathrm{PC}_{\text {Tech }}\right)$; and Panel $\mathrm{C}$ indicates predictive performance by taking economic and technical indicators simultaneously into account $\left(\mathrm{PC}_{\mathrm{All}}\right)$. The number of factors is selected according to the SIC information criterion. Additionally, we follow Ledoit and Wolf (2008) and test for equality of the Sharpe ratios between historical average forecasts and predictive regressions using the stationary block-bootstrap procedure of Politis and Romano (1994) with 5,000 repetitions and a block size of 5. We test the null hypothesis of equal or lower Sharpe ratio using historical average forecasts against the one-sided (upper-tail) alternative of higher Sharpe ratio using the predictive variable under analysis. Stars refer to significance level of $10 \%(*), 5 \%(* *)$, and $1 \%(* * *)$. 
Figure III: Time-varying Sharpe ratios of forecasting strategies, (transaction costs $=50 \mathrm{bp})$

Panel A: $\mathrm{PC}_{\text {Econ }}$

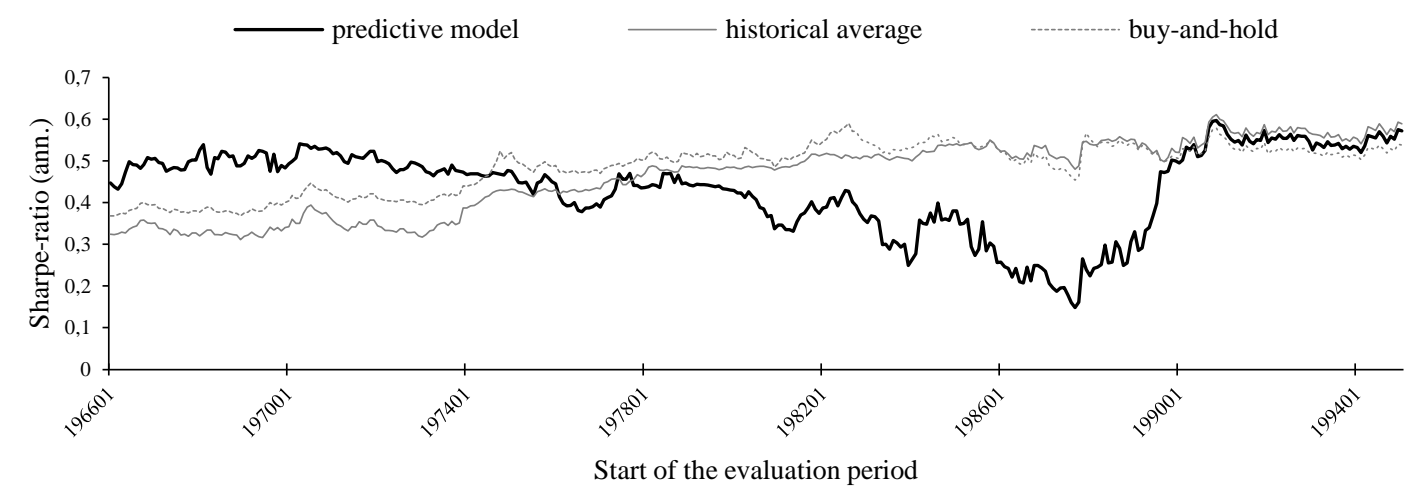

Panel B: $\mathrm{PC}_{\text {Tech }}$

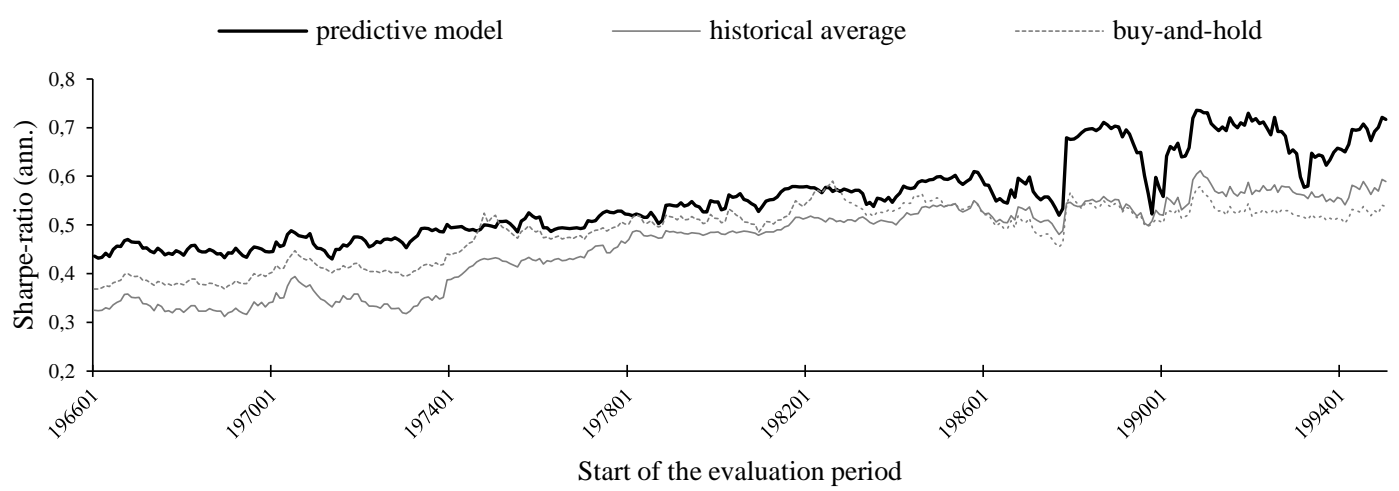

Panel C: $\mathrm{PC}_{\text {All }}$

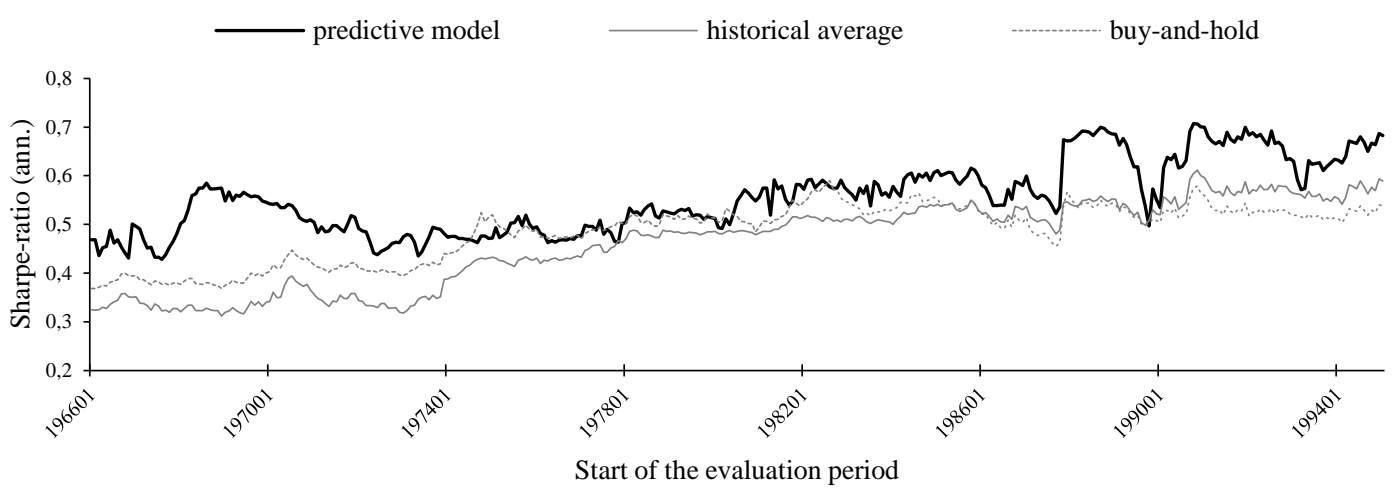

Notes: These figures show the time-varying annualized Sharpe ratio using a rolling-recursive estimation setting of forecasting strategies named in the headings. Our analysis starts with recursive forecast estimation over an initial insample estimation period of 15 years (1950:12-1965:12) and conduct real-time forecasts up to 2014:12. Next we discard the most distant data (i.e. 1950:12), yielding an in-sample estimation sample 1951:01-1966:01 (15 years) and perform out-of-sample forecasts up to 2014:12, the most recent data of our sample period. The beginning of the portfolio formation period is given on the x-axis. Thus the last Sharpe ratio corresponds to the sample period 1995:01-2014:12. We assume a relative risk-aversion coefficient of three and transaction costs of 50 basis points per monthly turnover. The black line shows the annualized Sharpe ratio of predictive regression forecasts, the grey solid line indicates the Sharpe ratio based on historical average forecasts and the grey dotted line corresponds to a simple buy-and-hold strategy. 
Figure IV: Time-varying realized utility of forecasting strategies, (transaction costs $=50 \mathrm{bp}$ )

Panel A: $\mathrm{PC}_{\text {Econ }}$

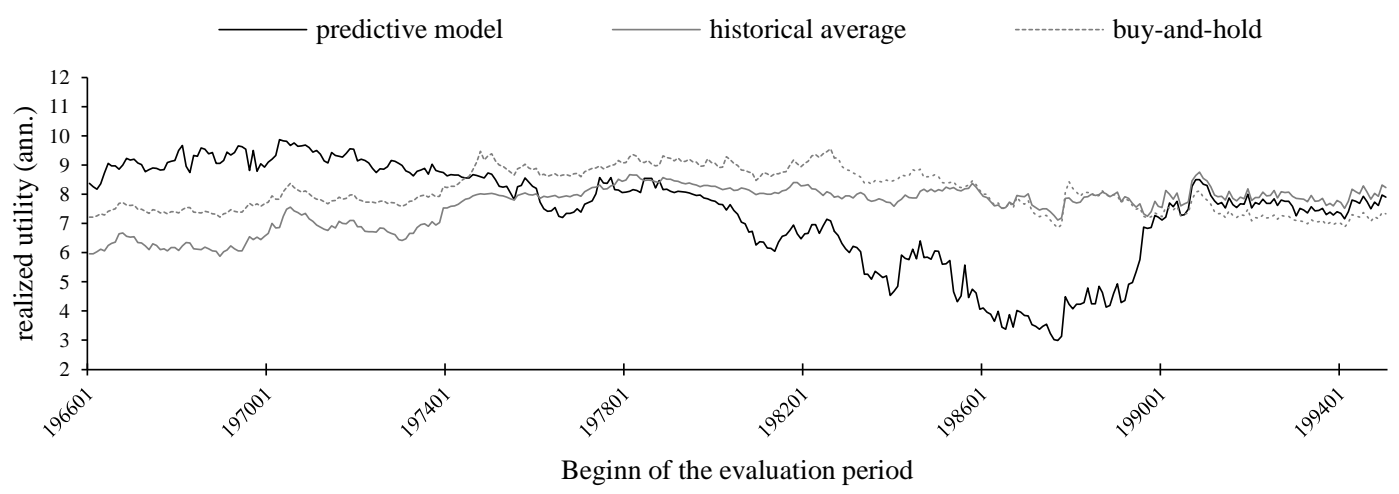

Panel B: $\mathrm{PC}_{\text {Tech }}$

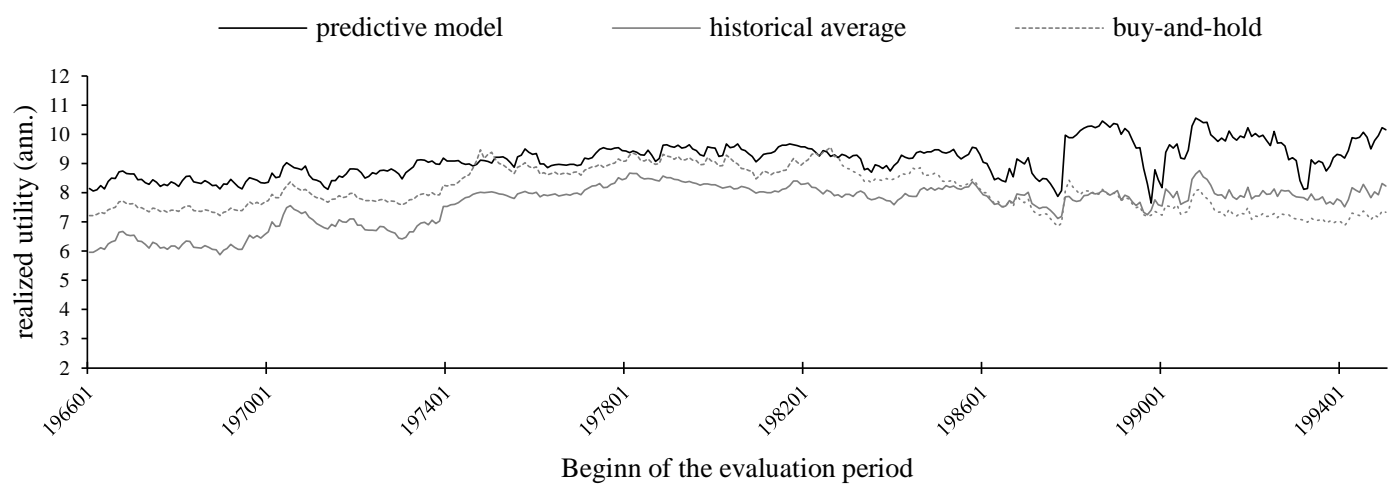

Panel C: $\mathrm{PC}_{\text {All }}$

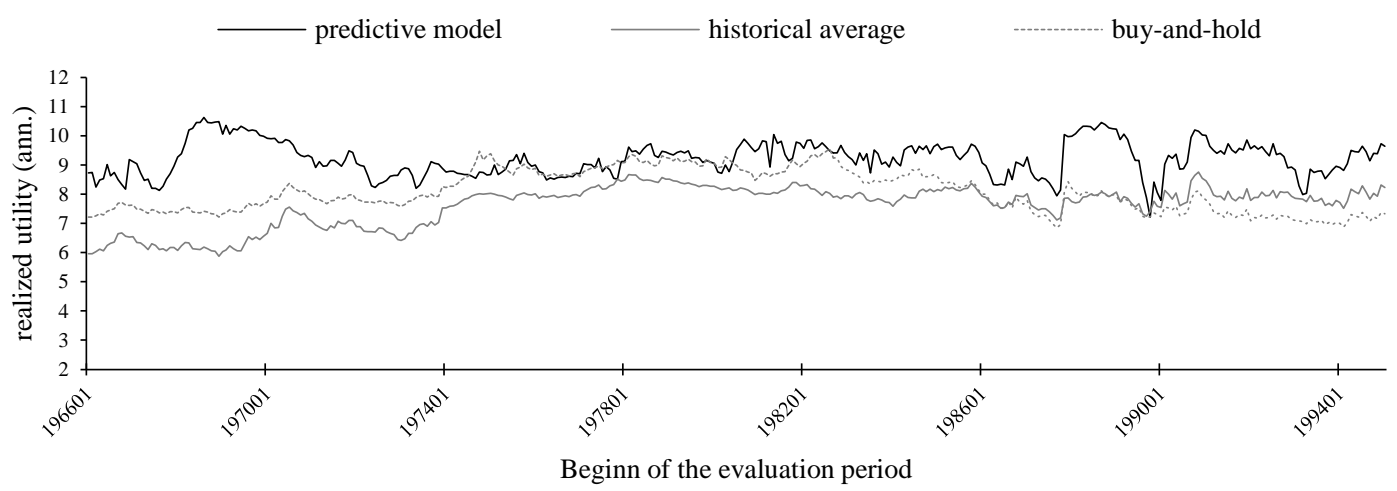

Notes: These figures show the time-varying annualized realized utility $\left(C E R_{p}=1200\left(\hat{\mu}_{p}-0.5 \gamma \hat{\sigma}_{p}^{2}\right)\right.$ using a rolling-recursive estimation setting of forecasting strategies named in the headings. Our analysis starts with recursive forecast estimation over an initial in-sample estimation period of 15 years (1950:12-1965:12) and conduct real-time forecasts up to 2014:12. Next we discard the most distant data (i.e. 1950:12), yielding an in-sample estimation sample 1951:01-1966:01 (15 years) and perform out-of-sample forecasts up to 2014:12, the most recent data of our sample period. The beginning of the portfolio formation period is given on the $\mathrm{x}$-axis. Thus the last $C E R$ corresponds to the sample period 1995:01-2014:12. We assume a relative risk-aversion coefficient of three and transaction costs of 50 basis points per monthly turnover. The black line shows the annualized CER of predictive regression forecasts, the grey solid line indicates the CER based on historical average forecasts and the grey dotted line corresponds to a simple buy-and-hold strategy. 


\section{APPENDIX}

to accompany

“Equity premium prediction: Are economic and technical indicators unstable?” 


\section{Appendix 1: Forecasting indicators and further tables}

\section{Technical indicators:}

1. Moving Average Rules (MA(s,l)): Moving average trading rules are defined as

$$
S_{i, t}=\left\{\begin{array}{l}
1 \text { if } M A_{s, t} \geq M A_{l, t} \quad s=(1,2,3) ; l=(9,12) \\
0 \text { otherwise }
\end{array}\right.
$$

where

$$
M A_{j, t}=\left(\frac{1}{j}\right) \sum_{i=0}^{j-1} P_{t-i} \quad \text { for } j=s, l
$$

$\mathrm{P}_{\mathrm{t}}$ is the level of the S\&P 500 stock price index.

2. Momentum Rules (MOM(m)): Momentum based trading rules are defined as

$$
S_{i, t}=\left\{\begin{array}{l}
1 \text { if } P_{t} \geq P_{t-m} \\
0 \text { otherwise }
\end{array} \quad \mathrm{m}=(6,12)\right.
$$

3. Volume Rules (VOL(s,l)): We follow Granville (1963) and make use of "onbalance" volume which is defined as

$$
O B V_{t}=\sum_{k=1}^{t} V O L_{k} D_{k}
$$

where $\mathrm{VOL}_{\mathrm{k}}$ is the monthly trading volume on the S\&P 500 index and $\mathrm{D}_{\mathrm{k}}$ takes a value of 1 if $P_{k}-P_{k-1} \geq 0$ and 0 otherwise (volume data on the S\&P 500 index is obtained and available at http://de.finance.yahoo.com). We then compare short$(s=1,2,3)$ and long-term $(l=9,12)$ moving averages to the OBV indicators to design trading signals.

$$
S_{i, t}=\left\{\begin{array}{l}
1 \text { if } M A_{s, t}^{O B V} \geq M A_{l, t}^{O B V} \\
0 \text { otherwise }
\end{array}\right.
$$

\section{Economic variables:}

1. Dividend Price Ratio (d/p): Defined as the difference between the log of a twelvemonth moving sum of dividends paid on the S\&P 500 index and the log of stock prices.

2. Dividend Yield (d/y): Defined as the difference between the log of a twelve-month moving sum of dividends paid on the S\&P 500 index and the log of lagged stock prices.

3. Earnings Price Ratio (e/p): Defined as the difference between the log of a twelvemonth moving sum of earnings on the S\&P 500 index and the log of stock prices.

4. Dividend Payout Ratio (d/e): Defined as the difference between the log of a twelvemonth moving sum of dividends paid on the S\&P 500 and the log of a twelve-month moving sum of earnings on the S\&P 500 . 
5. Equity Risk Premium Volatility (rvol): Following Neely et al. (2014) we make use of the volatility measure proposed by Mele (2007) to avoid problems arising from outliers in October 1987. Our equity risk premium volatility proxy is defined as

$$
\begin{aligned}
& \hat{\sigma}_{t}=\frac{1}{12} \sum_{i=1}^{12}\left|r_{t+1-i}\right| \\
& \widehat{\operatorname{rvol}}_{t} \equiv \sqrt{\frac{\pi}{2}} \sqrt{12} \hat{\sigma}_{t} .
\end{aligned}
$$

6. Book-to-Market Ratio (b/m): Defined as the ratio of book value to market value for the Dow Jones Industrial Average.

7. Net Equity Expansion (ntis): Defined as the ratio of a twelve-month moving sum of net equity issued by NYSE-listed stocks divided by the total end-of-year market capitalization of NYSE stocks.

8. Treasury Bill Rate (tbl): Defined as the 3-month Treasury bill rate (secondary market)

9. Long-term Yield (lty): Defined as the long-term government bond yield.

10. Long-term Return (ltr): Defined as the return on long-term government bonds.

11. Term Spread (tms): Defined as the difference between the long-term yield and the 3month Treasury bill rate.

12. Default Yield Spread (dfy): Defined as the difference between Moody’s BAA- and AAA- rated corporate bond yields.

13. Default Return Spread (dfr): Defined as the difference between the return on longterm corporate bonds and returns on long-term government bonds.

14. Inflation (infl): Calculated from the Consumer Price Index (CPI, All Urban Consumers). To account for a delay in CPI releases, we use the 1-month lagged inflation in the predictive regression. 


\section{Appendix 2: Robustness tests shortly mentioned in the main text}

This section presents robustness exercises in three directions: (1) We combine economic and technical indicators in various ways, (2) we demonstrate the small effect of various alternative specifications of volatility prediction models and (3) we examine the effect of alternative restrictions on portfolio formation, i.e. leveraged investments and shorting.

Alternative forecasting strategies. As mentioned above, forecasting strategies that incorporate much information avoid problems of in-sample overfitting, model uncertainty and parameter instability. To check whether reported results are robust, we first use different insample based selection criteria to determine the optimal number of factors used for equity premium predictability. In the following we apply the Akaike information criterion (AIC) in addition to the adjusted $R^{2}$, proposed by Neely et al. (2014). In contrast to principal component prediction which combines individual predictors in a data-driven manner we also employ forecast combinations, emphasized by Rapach et al. (2010) to check whether results remain stable. Such a procedure uses different weighting schemes to combine individual forecasting models without a possible lack of economic interpretation and appropriate factor selection through time. Combined forecasts are obtained by using mean, median and trimmed mean combination approaches as well as combination weights based on discounted mean squared forecasting errors (DMSFE). According to the DMSFE combination forecasts we consider two discount factors $\theta=1$ and $\theta=0.9$. A detailed description about the weighing schemes is given by Rapach et al. (2010).

In a nutshell, previous mentioned findings still hold for various alternative forecasting strategies. Table A.III reports the $R_{O S}^{2}$ over the evaluation period 1966:01-2014:12. Concerning the forecast performance of principal component predictive regressions based on economic variables or technical indicators (Panel A, B), we find only small differences compared to results given in Table A.I. In contrast, incorporating information from both predictor groups (Panel C) using either the AIC or the adjusted $R^{2}$ indicate a large increase in the $R_{O S}^{2}$ concentrated in recessions. The $R_{O S}^{2}$ solely rise to $1.56 \%$ (compared to $1.30 \%$ ) using the adjusted $R^{2}$ for factor selection. Forecast combinations on the other side, are extremely fruitful for economic information given by a statistically significant increase in the predictive performance located during expansions. Predictive performance of technical indicators on the 
other side is less affected due to the comparatively homogenous group variables. ${ }^{10}$ The outperformance of economic variables during expansion periods is even visible concerning forecast combinations based on economic variables and technical indicators. Nevertheless, the increase in the prediction performance during expansions comes at the cost of decreasing $R_{O S}^{2}$ during contraction periods.

TABLE A.III about here

Less affected is the time-varying stability of the equity premium prediction considered in Section 3.4. The time-varying process of the $R_{O S}^{2}$ seems to be largely independent whether we use principal components or forecast combinations (see Figure A.IV). Regarding economic variables, the statistical performance measure indicates a continuously diminishing value. While principal component predictive regressions exhibit a permanent negative $R_{O S}^{2}$, the outperformance of forecast combinations even become negative through time. As mentioned above, the spread between prediction performance during recessions and expansions sharply converge under more recent evaluation periods. The outperformance of technical indicators, on the other side, is quite more stable and confirms previous mentioned findings. Results by incorporating information from both predictor groups are strongly affected by the pathway of economic variables. The high outperformance reported in Table A.III is largely determined by an empirical relationship concentrated in the past.

FIGURE A.IV about here

A closer look at volatility prediction models. Expected utility maximization approaches require conditional mean and volatility forecasts, according to formula 8. Recent empirical research shows that economic variables have predictive power above and beyond autoregressive models even for financial volatility (see, for example, Cenesizoglu and Timmermann, 2012, Christiansen et al., 2012, Marquering and Verbeek, 2004). To verify whether our findings depend on volatility prediction specifications, we account for this kind of research by including predictor variables additional to the autoregressive term. Referring to equity premium prediction, we evaluate the following forecasting models

$$
\log \left(R V_{t+1}\right)=\alpha_{i}+\beta_{i} x_{i, t}+\rho_{i} \log \left(R V_{t}\right)+\varepsilon_{i, t+1}
$$

\footnotetext{
${ }^{10}$ Rapach et al. (2010) mention that forecast combinations lead to substantial reduction in forecast volatility. A rational explanation for the usefulness of forecast combinations of economic variables is given by its negative correlated between individual forecasts. Empirical findings can be found in Zhu and Zhu (2013). Due to the comparatively high correlation of forecasts using individual technical indicators such a reduction is less obvious.
} 
Thus, recursively estimated variance forecasts are obtained by $\exp \left(\hat{\alpha}_{i}+\hat{\beta}_{i} x_{i, s-1}+\right.$ $\left.\hat{\rho}_{i} \log \left(R V_{s-1}\right)\right)$ over the evaluation period 1966:01-2014:12. For convenience and comparison proposes, we use the same prediction models as for the equity premium and evaluate the forecast performance by the $R_{O S}^{2}$ using log returns, while economic forecast performance measures are based on simple returns. ${ }^{11}$ The responding benchmark model is based on a simple AR(1) specification, assuming $\beta_{i}=0$. Results are given in Table A.IV.

\section{TABLE A.IV about here}

In contrast to results reported for the equity premium, we find evidence that economic variables as well as technical indicators have statistical significant predictive power above and beyond a first-order autoregressive term. In detail, seven economic variables and thirteen technical indicators offer a positive $R_{O S}^{2}$ over the sample period. The outperformance of six economic variables is statistically significant at the $1 \%$ level and four at the $5 \%$ level. Concerning technical indicators, only two variables generate significant smaller prediction errors than the benchmark model at the $1 \%$ level. Nevertheless, for six (two) indicators the $R_{O S}^{2}$ is significant at the 5\% (10\%) level. More in line with previous results is the difference between the $R_{O S}^{2}$ during recessions and expansions. Not solely equity premium predictability seems to be a recession phenomenon, but also volatility prediction.

Principal component models highlight the beneficial use of such forecasting strategies. We find that combining information from economic variables and technical indicators yields the highest $R_{O S}^{2}$ of $5.73 \%$ over the evaluation period which is in line with previous findings. Even here the outperformance is mainly driven during recessions (16.24\%) compared to expansions (2.80\%).

However, looking at economic performance measures does not change our results considerably. Comparing Table A.II with Table A.V, we observe only mild deviations which do not change our general findings. Concerning differences in the annualized Sharpe ratio, the overall discrepancy is between -0.03 up to 0.01 .

TABLE A.V about here

Alternative specifications in portfolio allocation. Next, we analyze, how results differ according to variations of imposed portfolio constraints, relative risk aversion and under

\footnotetext{
${ }^{11}$ Full sample correlation between $R V$ based on squared daily log returns and squared daily simple returns is above 99\%. Thus, differences by using simple instead of log returns should not play any role.
} 
transaction costs. To address this question, Table A.VI reports differences in the realized utility. In addition, to shed light on any instability aspects, we show differences in the Sharpe ratio over the evaluation period 1966:01-2013:12 and difference in the average Sharpe ratio using our rolling-recursive estimation approach. All reported results are based on differences compared to asset allocations using the historical average forecast instead.

We allow for variation in the relative risk aversion, assuming coefficients of 3, 5, and 7. Portfolio allocation constraints are determined by: (a) short sales prevention and no leverage $\left(0 \leq w_{s-1} \leq 1\right)$, (b) short sales prevention and taking leverage by no more than $50 \%$ $\left(0 \leq w_{s-1} \leq 1.5\right)$, (c) allowing for short sales and taking leverage by $100 \%\left(-1 \leq w_{s-1} \leq\right.$ 2). Last but not least, we also analyze portfolio performance measures net of transaction costs, assuming costs of 50bp for reallocation purposes.

\section{TABLE A.VI about here}

Results reported in Table A.II indicate that alternative specifications do not change our general findings. In detail, the annualized Sharpe ratios of the prediction models compared with the benchmark specification indicate instabilities through time which is especially true for economic variables. The previously reported economic benefit of $\mathrm{PC}_{E c o n}$ disappears over time in nearly all cases. In accordance with the time-varying $R_{O S}^{2}$ it seems that the usefulness of economic variables is sample specific rather than systematic. We also find large variations for forecast combinations based on economic variables; however the average Sharpe ratio is mostly positive but small in magnitude.

On the other hand, imposing alternative allocation constraints and various relative risk aversion coefficients have only mild effects on the portfolio performance of technical indicators. While the economic benefit slightly decreases over time, the average Sharpe ratio is mostly positive which confirms the previously mentioned stability characteristics of technical indicators. Only if we allow for short selling, the economic importance vanishes through time using the adjusted $R^{2}$ as the model selection criterion.

Combining information from economic variables and technical indicators is also affected by instability pattern. The added economic value over the full sample largely declines over more recent subsamples which can be attributed to the poor performance of economic variables. Technical indicators on the other hand stabilize the added economic value, highlighting the importance of technical indicators as predictor variables. 
Table A.I: Out-of-sample forecasting evaluation

\begin{tabular}{|c|c|c|c|c|c|c|c|}
\hline Predictor & $R_{O S}^{2}$ & $\begin{array}{c}R_{O S}^{2} \\
\text { expansion }\end{array}$ & $\begin{array}{c}R_{O S}^{2} \\
\text { recession }\end{array}$ & Predictor & $R_{O S}^{2}$ & $\begin{array}{c}R_{O S}^{2} \\
\text { expansion }\end{array}$ & $\begin{array}{c}R_{O S}^{2} \\
\text { recession }\end{array}$ \\
\hline \multicolumn{8}{|c|}{ Panel A: Bivariate predictive regression forecasts } \\
\hline DP & $-0.22 \%$ & $-1.06 \%$ & $1.55 \% *$ & MA(1,9) & $0.31 \%$ & $-0.67 \%$ & $2.39 \% * *$ \\
\hline DY & $-0.17 \%$ & $-1.37 \%$ & $2.39 \% * *$ & $\mathrm{MA}(1,12)$ & $0.70 \% *$ & $-0.52 \%$ & $3.30 \% * *$ \\
\hline EP & $-0.58 \%$ & $-0.30 \%$ & $-1.17 \%$ & $\operatorname{MA}(2,9)$ & $0.39 \% *$ & $-0.61 \%$ & $2.54 \% * *$ \\
\hline $\mathrm{DE}$ & $-0.88 \%$ & $-1.72 \%$ & $0.89 \%$ & $\operatorname{MA}(2,12)$ & $0.85 \% * *$ & $-0.41 \%$ & $3.53 \% * *$ \\
\hline RVOL & $0.06 \% *$ & $-0.16 \%$ & $0.53 \%$ & MA(3,9) & $0.48 \% *$ & $-0.67 \%$ & $2.94 \% * *$ \\
\hline $\mathrm{BM}$ & $-1.26 \%$ & $-0.31 \%$ & $-3.30 \%$ & $\operatorname{MA}(3,12)$ & $0.09 \%$ & $-0.43 \%$ & $1.19 \%$ \\
\hline NTIS & $-0.91 \%$ & $-0.12 \% *$ & $-2.61 \%$ & $\operatorname{MOM}(6)$ & $0.17 \%$ & $-0.60 \%$ & $1.83 \% *$ \\
\hline TBL & $-0.84 \% * *$ & $-1.90 \% * *$ & $1.43 \% *$ & MOM(12) & $0.16 \%$ & $-0.41 \%$ & $1.39 \% *$ \\
\hline LTY & $-0.77 \% * *$ & $-1.58 \%$ & $0.98 \%$ & $\operatorname{VOL}(1,9)$ & $0.48 \% *$ & $-0.53 \%$ & $2.61 \% * *$ \\
\hline LTR & $0.26 \% * *$ & $-1.92 \%$ & $4.90 \% * * *$ & $\operatorname{VOL}(1,12)$ & $0.80 \% * *$ & $-0.20 \%$ & $2.94 \% * *$ \\
\hline TMS & $-0.84 \% * *$ & $-3.14 \%$ & $4.06 \% * *$ & $\operatorname{VOL}(2,9)$ & $0.47 \% *$ & $0.04 \%$ & $1.37 \% *$ \\
\hline DFY & $-0.63 \%$ & $-0.54 \%$ & $-0.83 \%$ & $\operatorname{VOL}(2,12)$ & $0.35 \%$ & $0.19 \%$ & $0.69 \%$ \\
\hline DFR & $-0.42 \%$ & $0.35 \% *$ & $-2.07 \%$ & $\operatorname{VOL}(3,9)$ & $0.03 \%$ & $-0.37 \%$ & $0.89 \%$ \\
\hline INFL & $-0.27 \%$ & $0.16 \%$ & $-1.19 \%$ & $\operatorname{VOL}(3,12)$ & $0.67 \% * *$ & $0.10 \%$ & $1.91 \% *$ \\
\hline \multicolumn{8}{|c|}{ Panel B: Principal component predictive regression forecasts } \\
\hline $\mathrm{PC}_{\text {Econ }}$ & $-0.61 \% * *$ & $-3.56 \%$ & $5.68 \% * *$ & $\mathrm{PC}_{\text {Tech }}$ & $0.71 \% *$ & $-0.33 \%$ & $2.93 \% * *$ \\
\hline \multicolumn{8}{|c|}{ Panel C: Principal component predictive regressions forecast, all predictors } \\
\hline $\mathrm{PC}_{\text {All }}$ & $1.30 \% * * *$ & $-1.43 \%$ & $7.10 \% * *$ & & & & \\
\hline
\end{tabular}

Notes: Table reports the out-of-sample $R_{O S}^{2}$ statistic proposed by Campbell and Thompson (2008) of log equity risk premium predictability over the evaluation period 1966:01 to 2014:12 and the predictive performance separately for NBER-dated expansions and recessions. Stars refer to significance level of $10 \%\left(^{*}\right), 5 \%\left({ }^{* *}\right)$, and $1 \%(* * *)$ of the MSFE-adj. test statistic proposed by Clark and West (2007). The MSFE-adj. statistics test the null hypothesis of equal or lower mean squared forecasting error (MSFE) using historical average forecasts against the one-sided (upper-tail) alternative of lower MSFE using the predictive variable under analysis. Panel A reveals results for bivariate predictive models; Panel B shows out-of-sample results using principal component extracted from the full set of macroeconomic variables $\left(\mathrm{PC}_{E c o n}\right)$ and technical indicators $\left(\mathrm{PC}_{T e c h}\right)$; and Panel $\mathrm{C}$ indicates predictive performance by taking economic and technical indicators simultaneously into account $\left(\mathrm{PC}_{\mathrm{All}}\right)$. The number of factor is selected according to the SIC information criterion. 
Figure A.I: Equity market volatility

Panel A: Log realized volatility

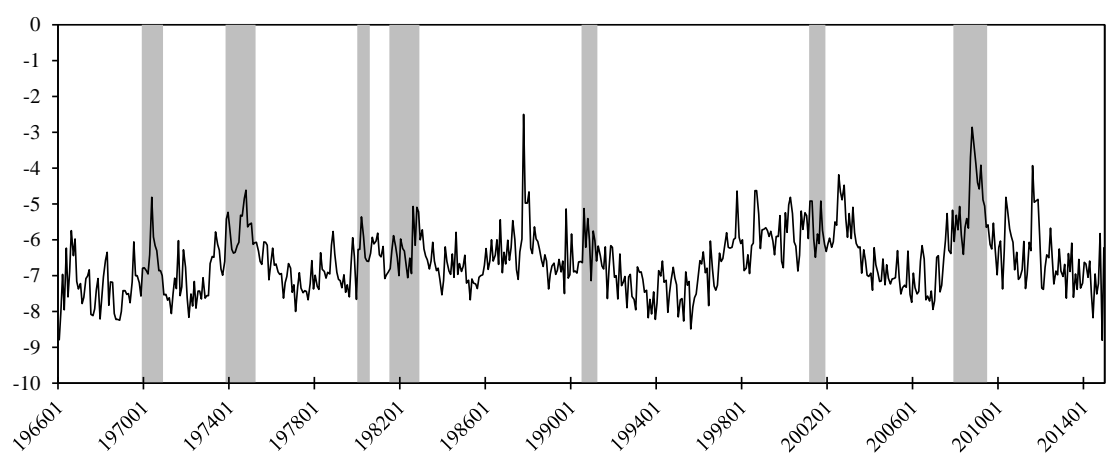

Panel B: Log realized volatility forecast, AR(1)

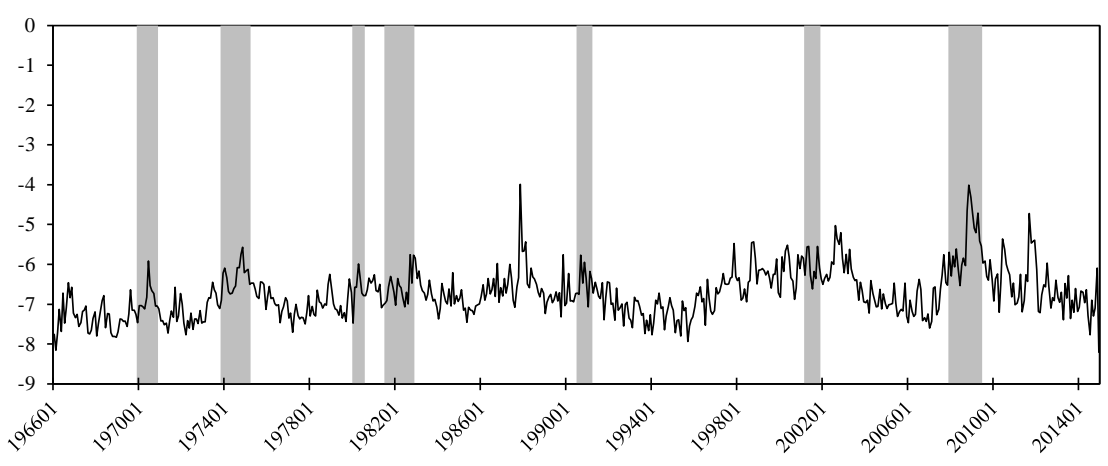

Notes: These figures show the realized volatility over the sample period 1966:01 through 2014:12. Panel A shows the log realized volatility while Panel B shows the corresponding out-of-sample forecast estimated recursively by an AR(1)-process. Shaded areas respond to NBER dated recessions. 
Table A.II: Economic measures of forecasting performance, (no transaction costs)

\begin{tabular}{lccccccccc}
\hline Predictor & Mean & Std. & $\begin{array}{c}\Delta \text { CER } \\
\text { (ann.) }\end{array}$ & SR & Predictor & Mean & Std. & $\begin{array}{c}\Delta \text { CER } \\
\text { (ann.) }\end{array}$ & SR \\
\hline HA & $1.00 \%$ & 5.32 & $6.91 \%$ & 0.38 & & & & &
\end{tabular}

Panel A: Bivariate predictive regression forecasts

\begin{tabular}{|c|c|c|c|c|c|c|c|c|c|}
\hline DP & $0.78 \%$ & 4.30 & $-0.91 \%$ & 0.29 & $\mathrm{MA}(1,9)$ & $0.98 \%$ & 4.88 & $0.62 \%$ & 0.40 \\
\hline DY & $0.74 \%$ & 4.22 & $-1.21 \%$ & 0.26 & $\mathrm{MA}(1,12)$ & $1.10 \%$ & 4.94 & $1.84 \%$ & 0.47 \\
\hline EP & $0.99 \%$ & 5.00 & $0.46 \%$ & 0.39 & $\mathrm{MA}(2,9)$ & $1.01 \%$ & 4.95 & $0.77 \%$ & 0.41 \\
\hline DE & $0.85 \%$ & 4.28 & $-0.01 \%$ & 0.35 & $\mathrm{MA}(2,12)$ & $1.11 \%$ & 4.93 & $2.03 \%$ & $0.48 *$ \\
\hline RVOL & $1.05 \%$ & 5.53 & $0.17 \%$ & 0.39 & $\mathrm{MA}(3,9)$ & $1.06 \%$ & 4.85 & $1.52 \%$ & 0.45 \\
\hline BM & $0.94 \%$ & 5.13 & $-0.43 \%$ & 0.35 & MA(3,12) & $1.00 \%$ & 5.03 & $0.49 \%$ & 0.39 \\
\hline NTIS & $0.99 \%$ & 5.38 & $-0.20 \%$ & 0.37 & $\operatorname{MOM}(6)$ & $0.96 \%$ & 4.93 & $0.23 \%$ & 0.38 \\
\hline TBL & $0.96 \%$ & 3.96 & $1.82 \%$ & 0.47 & MOM(12) & $1.00 \%$ & 5.15 & $0.38 \%$ & 0.39 \\
\hline LTY & $0.92 \%$ & 3.66 & $1.71 \%$ & 0.47 & $\operatorname{VOL}(1,9)$ & $1.02 \%$ & 5.02 & $0.76 \%$ & 0.41 \\
\hline LTR & $1.09 \%$ & 4.93 & $1.80 \%$ & 0.47 & $\operatorname{VOL}(1,12)$ & $1.07 \%$ & 4.88 & $1.64 \%$ & 0.46 \\
\hline TMS & $1.20 \%$ & 5.02 & $2.96 \%$ & $0.54 * *$ & $\operatorname{VOL}(2,9)$ & $1.04 \%$ & 5.14 & $0.85 \%$ & 0.42 \\
\hline DFY & $1.02 \%$ & 5.45 & $0.01 \%$ & 0.38 & $\operatorname{VOL}(2,12)$ & $1.03 \%$ & 5.10 & $0.73 \%$ & 0.41 \\
\hline DFR & $0.98 \%$ & 5.22 & $-0.02 \%$ & 0.37 & $\operatorname{VOL}(3,9)$ & $0.98 \%$ & 5.06 & $0.20 \%$ & 0.38 \\
\hline INFL & $0.99 \%$ & 4.82 & $0.80 \%$ & 0.41 & $\operatorname{VOL}(3,12)$ & $1.04 \%$ & 4.95 & $1.10 \%$ & 0.43 \\
\hline \multicolumn{10}{|c|}{ ncipal component predictive regression forecasts } \\
\hline $\mathrm{PC}_{\text {Econ }}$ & $1.01 \%$ & 3.87 & $2.50 \%$ & $0.52 *$ & $\mathrm{PC}_{\text {Tech }}$ & $1.12 \%$ & 4.98 & $2.03 \%$ & $0.48^{*}$ \\
\hline
\end{tabular}

Panel C: Principal component predictive regression forecasts, all predictors

$\begin{array}{lllll}\mathrm{PC}_{\text {All }} & 1.11 \% & 4.38 & 3.01 \% & 0.55 *\end{array}$

Notes: The Table reports means and standard deviations (Std.) of portfolio returns for a mean-variance investor with relative risk aversion coefficient of three over the sample period 1966:01-2014:12. $\Delta$ CER denotes the annualized certainty equivalent return gain of predictive regression forecasts in comparison to the historical average forecast and SR is the annualized Sharpe ratio defined as the average portfolio excess return divided by the sample standard deviation. Conditional variance forecasts are obtained by an AR(1) process of stock returns realized volatility. HA indicates the historical average forecast where portfolio performance measures are given in levels, Panel A reveals results for bivariate predictive models; Panel B shows results using principal component extracted from the full set of macroeconomic variables $\left(\mathrm{PC}_{E c o n}\right)$ and technical indicators $\left(\mathrm{PC}_{\text {Tech }}\right)$; and Panel $\mathrm{C}$ indicates predictive performance by taking economic and technical indicators simultaneously into account $\left(\mathrm{PC}_{\mathrm{All}}\right)$. The number of factor is selected according to the SIC information criterion. Additionally, we follow Ledoit and Wolf (2008) and test for equality of the Sharpe ratios between historical average forecasts and predictive regressions using the stationary block-bootstrap procedure of Politis and Romano (1994) with 5,000 repetitions and a block size of 5. We test the null hypothesis of equal or lower Sharpe ratio using historical average forecasts against the one-sided (upper-tail) alternative of higher Sharpe ratio using the predictive variable under analysis. Stars refer to significance level of $10 \%(*), 5 \%(* *)$, and $1 \%(* * *)$. 
Panel A: $\mathrm{PC}_{\text {Econ }}$

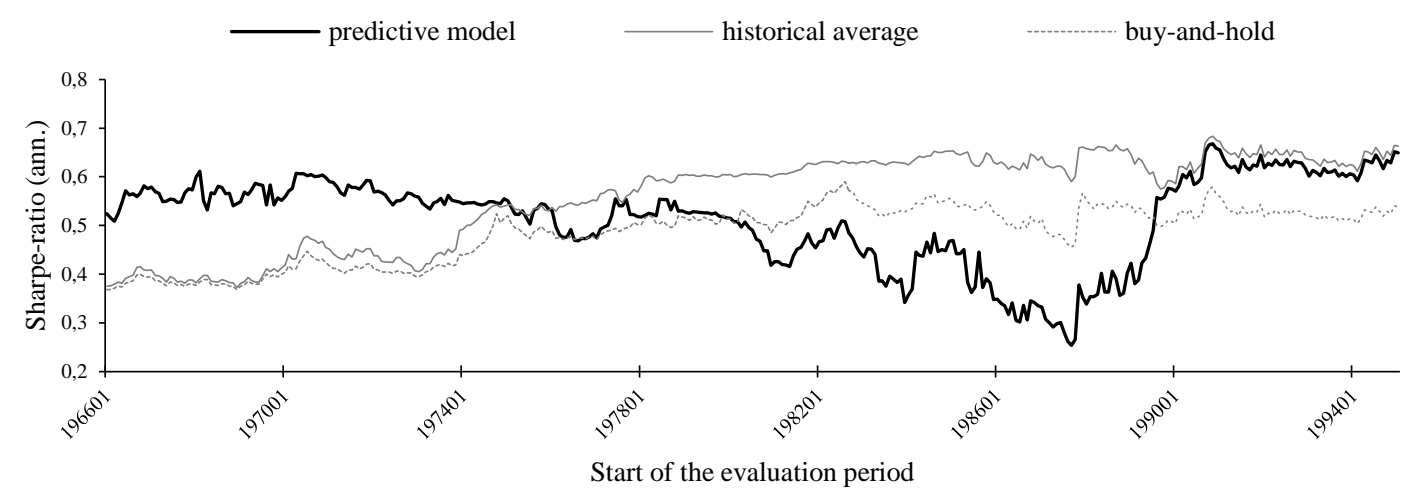

Panel B: $\mathrm{PC}_{\text {Tech }}$

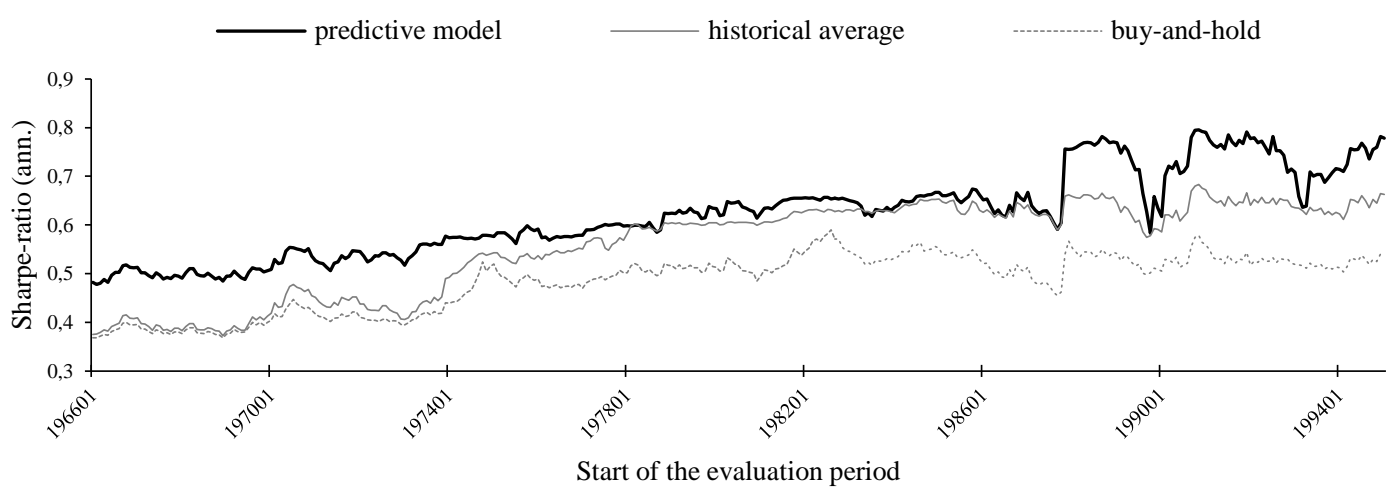

Panel C: $\mathrm{PC}_{\text {All }}$

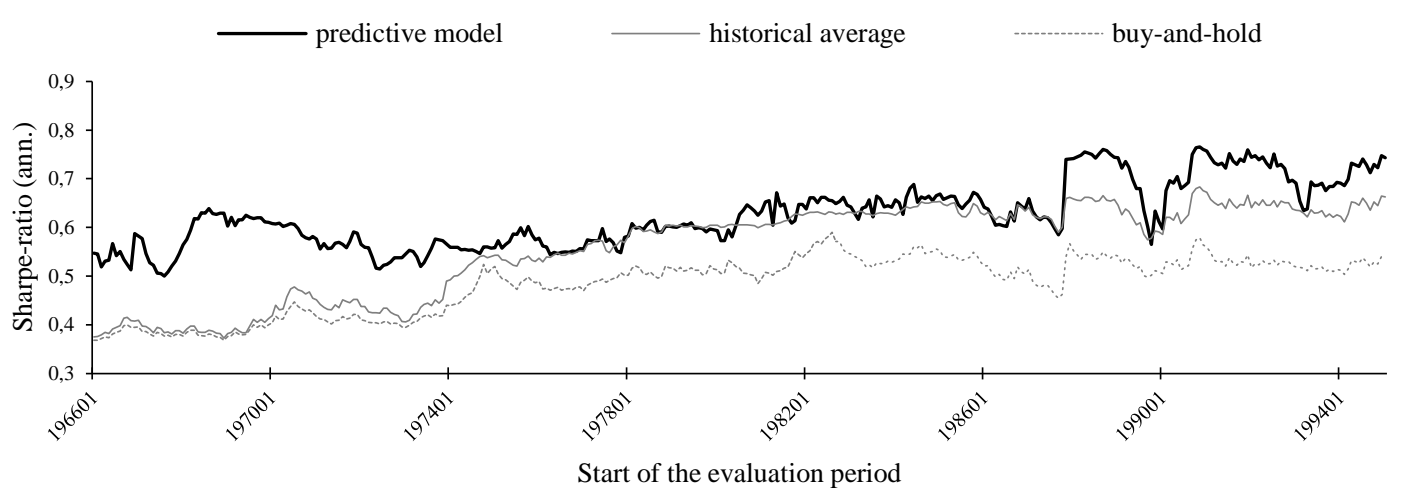

Notes: These figures show the time-varying annualized Sharpe ratio using a rolling-recursive estimation setting of forecasting strategies named in the headings. Our analysis starts with recursive forecast estimation over an initial in-sample estimation period of 15 years (1950:12-1965:12) and conduct real-time forecasts up to $2014: 12$. Next we discard the most distant data (i.e. 1950:12), yielding an in-sample estimation sample 1951:01-1966:01 (15 years) and perform out-of-sample forecasts up to 2014:12, the most recent data of our sample period. The beginning of the portfolio formation period is given on the $\mathrm{x}$-axis. Thus the last Sharpe ratio corresponds to the sample period 1995:01-2014:12. We assume a relative risk-aversion coefficient of three and zero transaction costs. The black line shows the annualized Sharpe ratio of predictive regression forecasts, the grey solid line indicates the Sharpe ratio based on historical average forecasts and the grey dotted line corresponds to a simple buy-and-hold strategy. 
Panel A: $\mathrm{PC}_{\text {Econ }}$

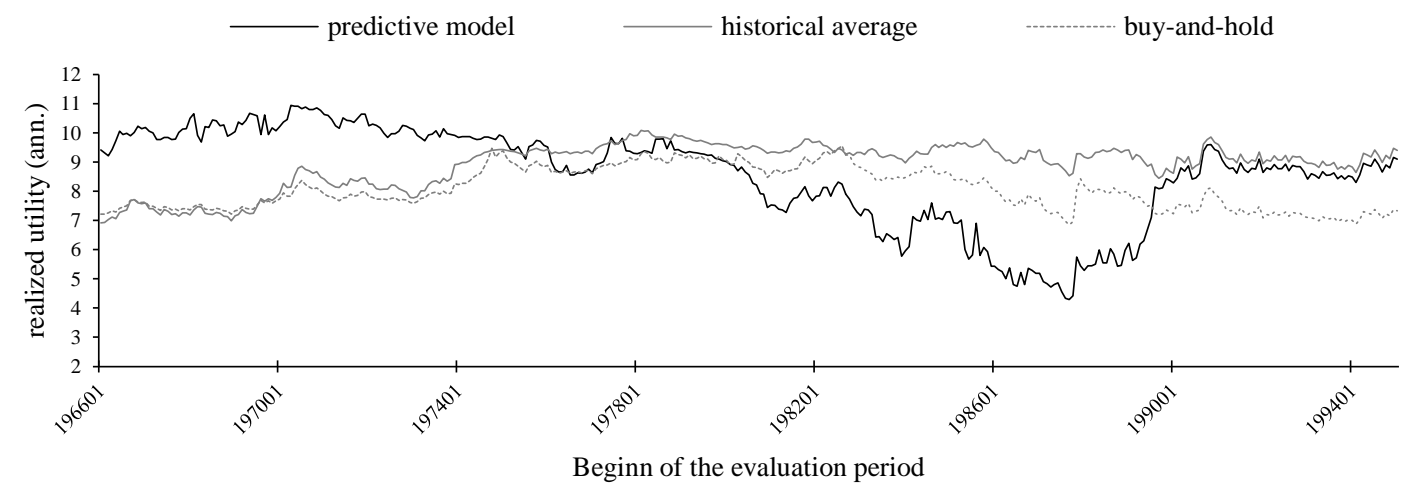

Panel B: $\mathrm{PC}_{\text {Tech }}$

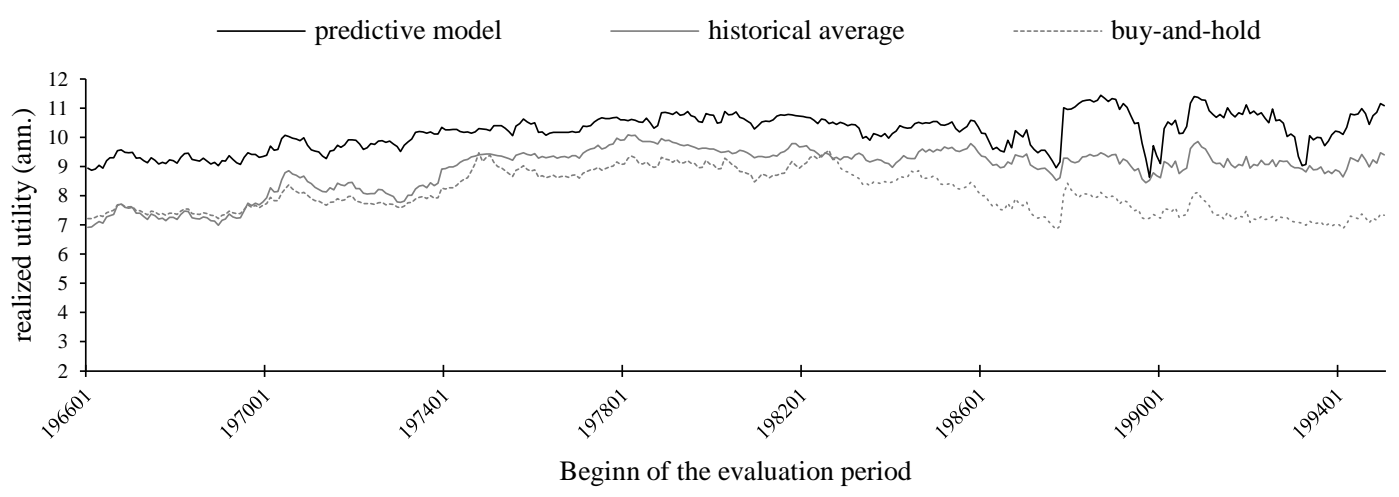

Panel C: $\mathrm{PC}_{\text {All }}$

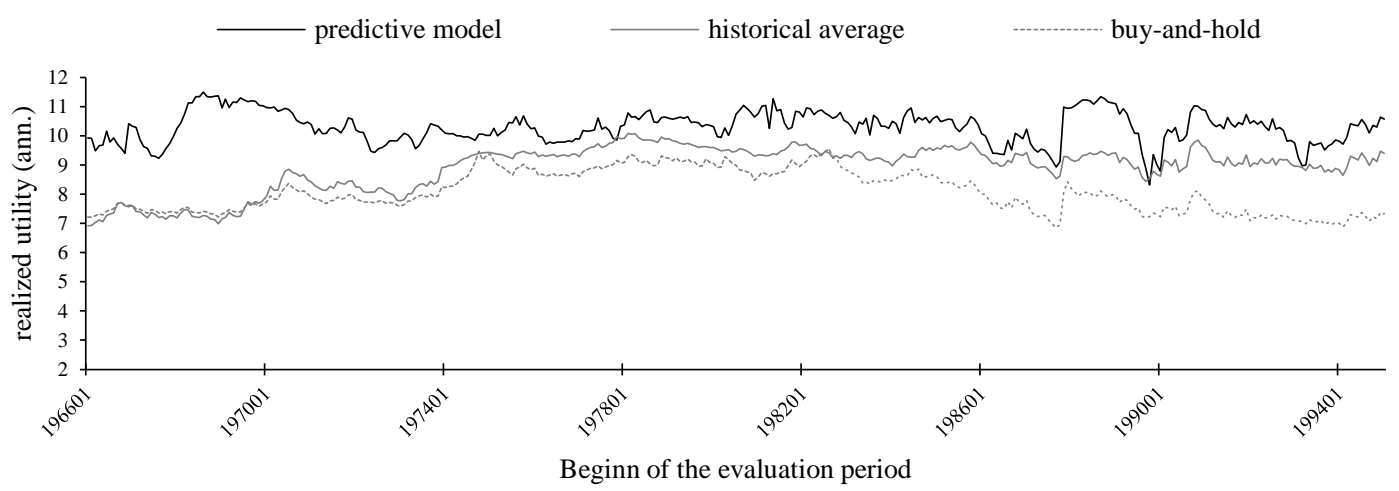

Notes: These figures show the time-varying annualized realized utility $\left(C E R_{p}=1200\left(\hat{\mu}_{p}-0.5 \gamma \hat{\sigma}_{p}^{2}\right)\right.$ using a rolling-recursive estimation setting of forecasting strategies named in the headings. Our analysis starts with recursive forecast estimation over an initial in-sample estimation period of 15 years (1950:12-1965:12) and conduct real-time forecasts up to 2014:12. Next we discard the most distant data (i.e. 1950:12), yielding an insample estimation sample 1951:01-1966:01 (15 years) and perform out-of-sample forecasts up to 2014:12, the most recent data of our sample period. The beginning of the portfolio formation period is given on the $\mathrm{x}$-axis. Thus the last CER corresponds to the sample period 1995:01-2014:12. We assume a relative risk-aversion coefficient of three and zero transaction costs. The black line shows the annualized CER of predictive regression forecasts, the grey solid line indicates the CER based on historical average forecasts and the grey dotted line corresponds to a simple buy-and-hold strategy. 
Table A.III: Out-of-sample forecasting evaluation using alternative pooling strategies

\begin{tabular}{lccc}
\hline Pooling strategy & $R_{O S}^{2}$ & $\begin{array}{c}R_{O S}^{2} \\
\text { expansion }\end{array}$ & $\begin{array}{c}R_{O S}^{2} \\
\text { recession }\end{array}$ \\
\hline \multicolumn{2}{l}{ Panel A: Principal component predictive regression and combination forecasts; Econ } & \\
Adj. $R^{2}$ & $-0.81 \%^{* * *}$ & $-3.80 \%^{*}$ & $5.56 \%^{* *}$ \\
AIC & $-0.90 \% * * *$ & $-4.09 \%^{*}$ & $5.90 \%^{* *}$ \\
Mean & $1.15 \% * * *$ & $0.75 \% * * *$ & $2.00 \%^{* *}$ \\
Median & $0.69 \%^{* * *}$ & $0.61 \%^{* *}$ & $0.85 \%^{* *}$ \\
Trimmed Mean & $1.06 \%^{* * *}$ & $0.73 \%^{* * *}$ & $1.76 \%^{* *}$ \\
DMSPE(1.0) & $1.18 \%^{* * *}$ & $0.80 \% * * *$ & $1.99 \%^{* *}$ \\
DMSPE(0.9) & $1.19 \%^{* * *}$ & $0.73 \%^{* *}$ & $2.18 \% \%^{* *}$
\end{tabular}

Panel B: Principal component predictive regression and combination forecasts; Tech

$\begin{array}{lccc}\text { Adj. } R^{2} & 0.29 \% & -0.59 \% & 2.17 \% * \\ \text { AIC } & 0.58 \%^{*} & -0.52 \% & 2.93 \%^{* *} \\ \text { Mean } & 0.57 \%^{*} & -0.19 \% & 2.19 \%^{* *} \\ \text { Median } & 0.74 \%^{* *} & -0.05 \% & 2.42 \%^{* *} \\ \text { Trimmed Mean } & 0.63 \%^{*} & -0.12 \% & 2.21 \%^{* *} \\ \text { DMSPE(1.0) } & 0.57 \%^{*} & -0.19 \% & 2.19 \%^{* *} \\ \text { DMSPE(0.9) } & 0.58 \% * & -0.19 \% & 2.21 \%^{* *}\end{array}$

Panel C: Principal component predictive regression and combination forecasts; All

$\begin{array}{lccc}\text { Adj. } R^{2} & 1.56 \% * * * & -2.53 \% * & 10.28 \% * * * \\ \text { AIC } & 0.63 \% * * * & -2.82 \% & 7.97 \% * * * \\ \text { Mean } & 0.96 \% * * * & 0.40 \% * & 2.17 \% * * \\ \text { Median } & 0.91 \% * * & 0.27 \% & 2.28 \% \%^{* *} \\ \text { Trimmed Mean } & 0.91 \% * * * & 0.37 \% * & 2.07 \% * * \\ \text { DMSPE(1.0) } & 1.02 \% * * * & 0.47 \% * * & 2.18 \% * * \\ \text { DMSPE(0.9) } & 1.02 \% * * * & 0.42 \% * & 2.28 \%^{* *}\end{array}$

Note: This table shows various specifications (Adj. $R^{2}$ and AIC) to determine the maximum number of common factors used for principal component predictive regressions. We also make use of forecast combinations (following Rapach et al., 2010) as an alternative to incorporate individual information. Presented results indicate the out-of-sample $R_{O S}^{2}$ statistic proposed by Campbell and Thompson (2008) for the sample period 1966:01 to 2014:12 and the predictive performance separately for NBER-dated expansions and recessions. Stars refer to significance level of $10 \%(*), 5 \%(* *)$ and $1 \%(* * *)$ of the MSFE-adj. test statistic proposed by Clark and West (2007). The MSFE-adj. statistics test the null hypothesis of equal or lower mean squared forecasting error (MSFE) using historical average forecasts against the one-sided (upper-tail) alternative of lower MSFE using the predictive variable under analysis. 

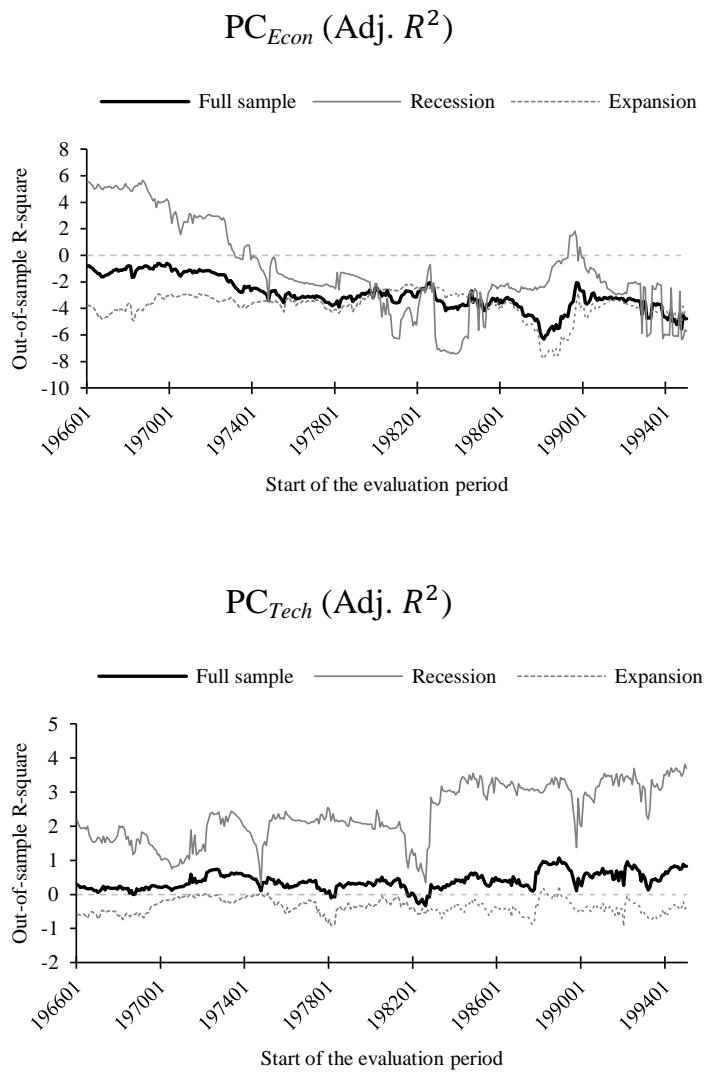

$\mathrm{PC}_{\text {All }}\left(\right.$ Adj. $\left.R^{2}\right)$

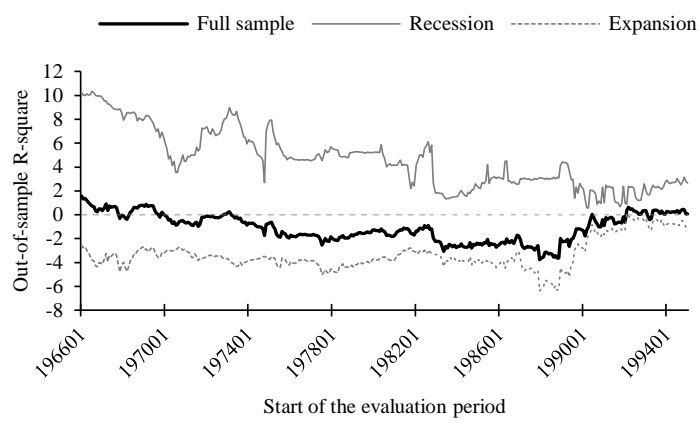

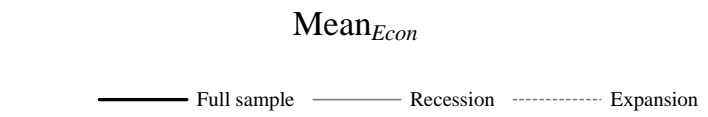

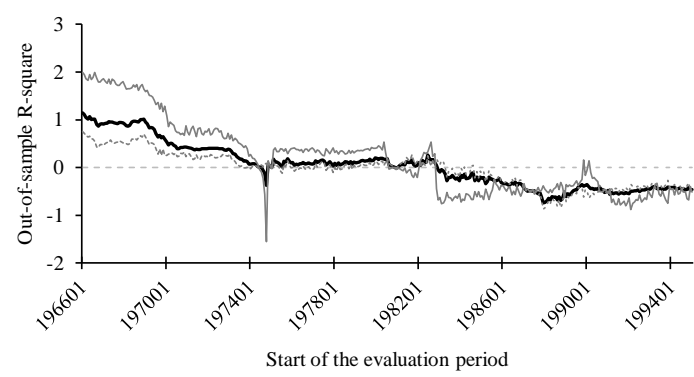

$\operatorname{Mean}_{\text {Tech }}$

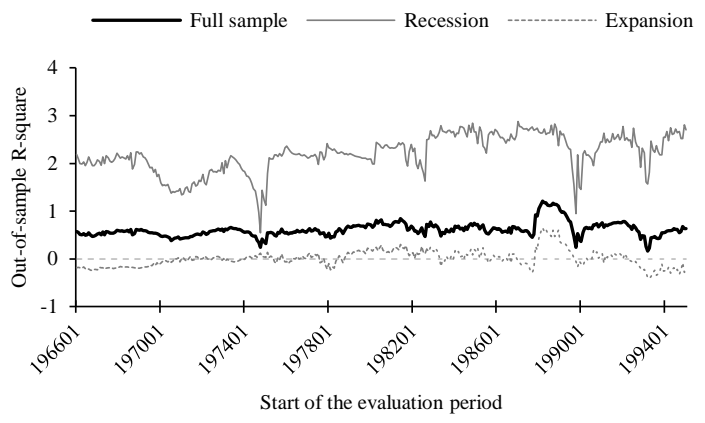

Mean $_{\text {All }}$

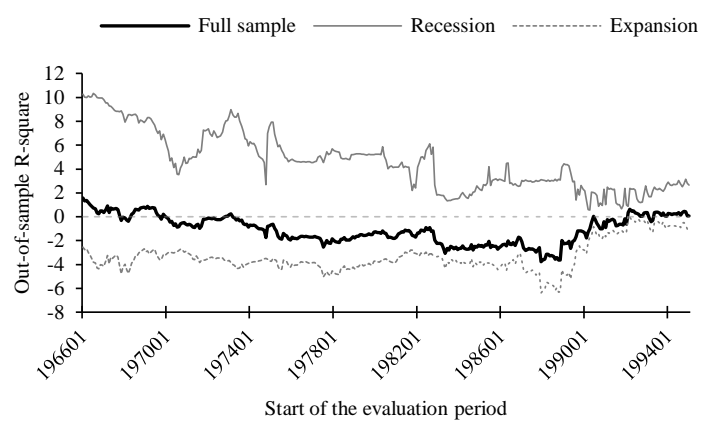

Notes: These figures show the time-varying out-of-sample predictive performance measured by the $R_{O S}^{2}$, using a rolling-recursive estimation setting. Our analysis starts with recursive forecast estimation over an initial insample estimation period of 15 years (1950:12-1965:12) and conduct real-time forecasts up to 2014:12. Next we discard the most distant data (i.e. 1950:12), yielding an in-sample estimation sample 1951:01-1966:01 (15 years) and perform out-of-sample forecasts up to 2014:12, the most recent data of our sample period. The beginning of the out-of-sample evaluation period is given on the x-axis. Thus the last $R_{O S}^{2}$ is obtained over the sample period 1995:01-2014:12. The black line shows the time-varying $R_{O S}^{2}$, the grey solid line signals the $R_{O S}^{2}$ regarding recessions and the grey dotted line corresponds to the $R_{O S}^{2}$ over expansions. Corresponding predictive regressions are named in the headings 
Table A.IV: Out-of-sample forecasting evaluation (log realized volatility)

\begin{tabular}{|c|c|c|c|c|c|c|c|}
\hline Predictor & $R_{O S}^{2}$ & $\begin{array}{c}R_{O S}^{2} \\
\text { expansion }\end{array}$ & $\begin{array}{c}R_{O S}^{2} \\
\text { recession }\end{array}$ & Predictor & $R_{O S}^{2}$ & $\begin{array}{c}R_{O S}^{2} \\
\text { expansion }\end{array}$ & $\begin{array}{c}R_{O S}^{2} \\
\text { recession }\end{array}$ \\
\hline \multicolumn{8}{|c|}{ Panel A: Bivariate predictive regression forecasts } \\
\hline DP & $1.10 \% * * *$ & $0.42 \% *$ & $3.52 \% * * *$ & $\mathrm{MA}(1,9)$ & $0.84 \% * * *$ & $0.12 \% *$ & $3.43 \% * * *$ \\
\hline DY & $1.68 \% * * *$ & $1.29 \% * * *$ & $3.07 \% * *$ & $\mathrm{MA}(1,12)$ & $0.73 \% * *$ & $-0.56 \%$ & $5.40 \% * * *$ \\
\hline EP & $0.49 \% * *$ & $-1.79 \%$ & $8.68 \% * * *$ & $\operatorname{MA}(2,9)$ & $0.09 \%$ & $-0.71 \%$ & $2.95 \% * * *$ \\
\hline $\mathrm{DE}$ & $-0.88 \% * * *$ & $-2.57 \% * *$ & $5.21 \% * *$ & $\operatorname{MA}(2,12)$ & $0.50 \% * *$ & $-0.86 \%$ & $5.35 \% * * *$ \\
\hline RVOL & $2.20 \% * * *$ & $2.85 \% * * *$ & $-0.12 \%$ & MA(3,9) & $0.15 \% *$ & $-1.17 \%$ & $4.86 \% * * *$ \\
\hline BM & $-0.07 \% * *$ & $-3.83 \%$ & $13.44 \% * * *$ & $\mathrm{MA}(3,12)$ & $0.53 \% * *$ & $-0.83 \%$ & $5.39 \% * * *$ \\
\hline NTIS & $0.67 \% * *$ & $-0.15 \% *$ & $3.61 \% * *$ & $\operatorname{MOM}(6)$ & $0.71 \% * *$ & $-0.36 \%$ & $4.56 \% * * *$ \\
\hline TBL & $-0.90 \% * *$ & $-2.31 \%$ & $4.17 \% * *$ & MOM(12) & $0.77 \% * *$ & $-0.50 \%$ & $5.33 \% * * *$ \\
\hline LTY & $-0.22 \% * * *$ & $-1.78 \% *$ & $5.31 \% * * *$ & $\operatorname{VOL}(1,9)$ & $0.71 \% * *$ & $-0.31 \%$ & $4.39 \% * * *$ \\
\hline LTR & $-0.57 \%$ & $-0.37 \%$ & $-1.27 \%$ & $\operatorname{VOL}(1,12)$ & $1.32 \% * * *$ & $0.07 \%$ & $5.83 \% * * *$ \\
\hline TMS & $-0.25 \%$ & $-0.53 \%$ & $0.78 \%$ & $\operatorname{VOL}(2,9)$ & $-0.30 \%$ & $-0.65 \%$ & $0.94 \% * *$ \\
\hline DFY & $2.35 \% * * *$ & $0.39 \% * *$ & $9.37 \% * * *$ & $\operatorname{VOL}(2,12)$ & $0.14 \%$ & $-0.43 \%$ & $2.17 \% * * *$ \\
\hline DFR & $0.14 \%$ & $-0.19 \%$ & $1.30 \%$ & $\operatorname{VOL}(3,9)$ & $0.05 \%$ & $-0.51 \%$ & $2.06 \% * * *$ \\
\hline INFL & $-0.24 \%$ & $-1.18 \%$ & $3.14 \% * *$ & $\operatorname{VOL}(3,12)$ & $0.37 \% *$ & $-0.72 \%$ & $3.60 \% * * *$ \\
\hline \multicolumn{8}{|c|}{ Panel B: Principal component predictive regression forecasts } \\
\hline $\mathrm{PC}_{\text {Econ }}$ & $4.12 \% * * *$ & $0.86 \% * * *$ & $15.83 \% * * *$ & $\mathrm{PC}_{\text {Tech }}$ & $0.87 \% * * *$ & $-0.65 \%$ & $6.34 \% * * *$ \\
\hline \multicolumn{8}{|c|}{$\underline{\text { Panel C: Principal component predictive regression forecasts, all predictors }}$} \\
\hline $\mathrm{PC}_{\text {All }}$ & $5.73 \% * * *$ & $2.80 \% * * *$ & $16.24 \% * * *$ & & & & \\
\hline
\end{tabular}

Notes: Table reports the out-of-sample $R_{O S}^{2}$ statistic proposed by Campbell and Thompson (2008) of log realized volatility predictability over the evaluation period 1966:01 to 2014:12 and the predictive performance separately for NBER-dated expansions and recessions. Stars refer to significance level of $10 \%(*), 5 \%(* *)$, and $1 \%(* * *)$ of the MSFE-adj. test statistic proposed by Clark and West (2007). The MSFE-adj. statistics test the null hypothesis of equal or lower mean squared forecasting error (MSFE) under the benchmark specification (AR(1)process) against the one-sided (upper-tail) alternative of lower MSFE by additional consideration of the predictive variable under analysis. Panel A reveals results for bivariate predictive models; Panel B shows out-ofsample results using principal component extracted from the full set of macroeconomic variables $\left(\mathrm{PC}_{E c o n}\right)$ and technical indicators $\left(\mathrm{PC}_{T e c h}\right)$; and Panel $\mathrm{C}$ indicates predictive performance by taking economic and technical indicators simultaneously into account $\left(\mathrm{PC}_{A l l}\right)$. The number of factor is selected according to the SIC information criterion. 
Table A.V: Economic value of equity premium and volatility forecasts (no transaction costs)

\begin{tabular}{|c|c|c|c|c|c|c|c|c|c|}
\hline Predictor & Mean & Std. & $\begin{array}{l}\Delta \text { CER } \\
\text { (ann.) }\end{array}$ & SR & Predictor & Mean & Std. & $\begin{array}{l}\mathrm{CERR} \\
\text { (ann.) }\end{array}$ & SR \\
\hline HA & $1.00 \%$ & 5.32 & $6.91 \%$ & 0.38 & & & & & \\
\hline
\end{tabular}

Panel A: Bivariate predictive regression forecasts

\begin{tabular}{|c|c|c|c|c|c|c|c|c|c|}
\hline DP & $0.77 \%$ & 4.29 & $-0.95 \%$ & 0.28 & MA(1,9) & $1.00 \%$ & 4.89 & $0.75 \%$ & 0.41 \\
\hline DY & $0.74 \%$ & 4.21 & $-1.26 \%$ & 0.26 & $\operatorname{MA}(1,12)$ & $1.10 \%$ & 4.94 & $1.95 \%$ & 0.48 \\
\hline EP & $0.99 \%$ & 5.07 & $0.40 \%$ & 0.39 & $\operatorname{MA}(2,9)$ & $1.01 \%$ & 4.94 & $0.85 \%$ & 0.41 \\
\hline $\mathrm{DE}$ & $0.83 \%$ & 4.26 & $-0.16 \%$ & 0.33 & $\operatorname{MA}(2,12)$ & $1.12 \%$ & 4.92 & $2.15 \%$ & $0.49 *$ \\
\hline RVOL & $1.04 \%$ & 5.57 & $0.03 \%$ & 0.39 & $\operatorname{MA}(3,9)$ & $1.06 \%$ & 4.84 & $1.61 \%$ & 0.46 \\
\hline BM & $0.94 \%$ & 5.17 & $-0.44 \%$ & 0.35 & MA(3,12) & $1.01 \%$ & 5.04 & $0.62 \%$ & 0.40 \\
\hline NTIS & $1.00 \%$ & 5.38 & $-0.13 \%$ & 0.37 & MOM(6) & $0.97 \%$ & 4.93 & $0.36 \%$ & 0.38 \\
\hline TBL & $0.97 \%$ & 4.04 & $1.81 \%$ & 0.47 & MOM(12) & $1.02 \%$ & 5.18 & $0.49 \%$ & 0.40 \\
\hline LTY & $0.92 \%$ & 3.71 & $1.70 \%$ & 0.47 & VOL $(1,9)$ & $1.03 \%$ & 5.01 & $0.88 \%$ & 0.42 \\
\hline LTR & $1.09 \%$ & 4.94 & $1.80 \%$ & 0.47 & $\operatorname{VOL}(1,12)$ & $1.08 \%$ & 4.88 & $1.81 \%$ & 0.47 \\
\hline TMS & $1.20 \%$ & 5.01 & $2.93 \%$ & $0.53^{* *}$ & $\operatorname{VOL}(2,9)$ & $1.05 \%$ & 5.14 & $0.91 \%$ & 0.42 \\
\hline DFY & $1.02 \%$ & 5.46 & $-0.06 \%$ & 0.38 & $\operatorname{VOL}(2,12)$ & $1.04 \%$ & 5.11 & $0.81 \%$ & 0.41 \\
\hline DFR & $0.98 \%$ & 5.23 & $-0.02 \%$ & 0.34 & $\operatorname{VOL}(3,9)$ & $0.98 \%$ & 5.07 & $0.25 \%$ & 0.38 \\
\hline INFL & $1.00 \%$ & 4.84 & $0.83 \%$ & 0.41 & $\operatorname{VOL}(3,12)$ & $1.05 \%$ & 4.96 & $1.21 \%$ & 0.43 \\
\hline & & & & & & & & & \\
\hline $\mathrm{PC}_{\text {Econ }}$ & $0.99 \%$ & 3.88 & $2.30 \%$ & 0.51 & $\mathrm{PC}_{\text {Tech }}$ & $1.13 \%$ & 4.98 & $2.17 \%$ & $0.49 *$ \\
\hline
\end{tabular}

Panel C: Predictive regressions, all predictors taken together

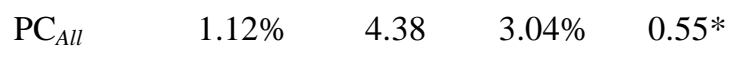

Notes: The Table reports means and standard deviations (Std.) of portfolio returns for a mean-variance investor with relative risk aversion coefficient of three over the sample period 1966:01-2014:12. Portfolio performance measures are based on both equity premium and volatility forecasts using the predictive variable being analyzed. $\triangle \mathrm{CER}$ denotes the annualized certainty equivalent return gain of predictive regression forecasts in comparison to the historical average forecast and SR is the annualized Sharpe ratio defined as the average portfolio excess return divided by the sample standard deviation. HA indicates the historical average forecast where portfolio performance measures are given in levels, Panel A reveals results for bivariate predictive models; Panel B shows results using principal component extracted from the full set of macroeconomic variables $\left(\mathrm{PC}_{E c o n}\right)$ and technical indicators $\left(\mathrm{PC}_{\mathrm{Tech}}\right)$; and Panel $\mathrm{C}$ indicates predictive performance by taking economic and technical indicators simultaneously into account $\left(\mathrm{PC}_{\mathrm{All}}\right)$. The number of factor is selected according to the SIC information criterion. Additionally, we follow Ledoit and Wolf (2008) and test for equality of the Sharpe ratios between historical average forecasts and predictive regressions using the stationary block-bootstrap procedure of Politis and Romano (1994) with 5,000 repetitions and a block size of 5. We test the null hypothesis of equal or lower Sharpe ratio using historical average forecasts against the one-sided (upper-tail) alternative of higher Sharpe ratio using the predictive variable under analysis. Stars refer to significance level of $10 \%(*), 5 \%(* *)$, and $1 \%(* * *)$. 
Table A.VI: Alternative settings for forecast performance evaluation

\begin{tabular}{|c|c|c|c|c|c|c|c|c|c|c|c|c|c|c|c|c|c|c|}
\hline & \multicolumn{18}{|c|}{ (a) Relative risk aversion: $\gamma=3$} \\
\hline & \multicolumn{6}{|c|}{$0 \leq w_{s} \leq 1$} & \multicolumn{6}{|c|}{$0 \leq w_{s} \leq 1.5$} & \multicolumn{6}{|c|}{$-1 \leq w_{s} \leq 2$} \\
\hline & \multicolumn{3}{|c|}{$\mathrm{c}=0$} & \multicolumn{3}{|c|}{$\mathrm{c}=50$} & \multicolumn{3}{|c|}{$\mathrm{c}=0$} & \multicolumn{3}{|c|}{$\mathrm{c}=50$} & \multicolumn{3}{|c|}{$\mathrm{c}=0$} & \multicolumn{3}{|c|}{$\mathrm{c}=50$} \\
\hline & $\begin{array}{l}\Delta \text { CER } \\
\text { (ann.) }\end{array}$ & $\Delta \mathrm{SR}$ & $\begin{array}{l}\text { Avg. } \\
\Delta \mathrm{SR}\end{array}$ & $\begin{array}{l}\Delta \text { CER } \\
\text { (ann.) }\end{array}$ & $\Delta \mathrm{SR}$ & $\begin{array}{l}\text { Avg. } \\
\Delta \text { SR }\end{array}$ & $\begin{array}{l}\Delta \text { CER } \\
\text { (ann.) }\end{array}$ & $\Delta \mathrm{SR}$ & $\begin{array}{l}\text { Avg. } \\
\Delta \text { SR }\end{array}$ & $\begin{array}{l}\Delta \text { CER } \\
\text { (ann.) }\end{array}$ & $\Delta \mathrm{SR}$ & $\begin{array}{l}\text { Avg. } \\
\Delta \text { SR }\end{array}$ & $\begin{array}{l}\Delta \text { CER } \\
\text { (ann.) }\end{array}$ & $\Delta \mathrm{SR}$ & $\begin{array}{l}\text { Avg. } \\
\Delta \text { SR }\end{array}$ & $\begin{array}{l}\Delta \text { CER } \\
\text { (ann.) }\end{array}$ & $\Delta \mathrm{SR}$ & $\begin{array}{l}\text { Avg. } \\
\Delta \text { SR }\end{array}$ \\
\hline $\mathrm{PC}_{\text {Econ }}(\mathrm{SIC})$ & $0.50 \%$ & 0.06 & -0.02 & $0.19 \%$ & 0.02 & -0.02 & $2.50 \%$ & 0.15 & -0.04 & $2.41 \%$ & 0.12 & -0.03 & $2.34 \%$ & 0.08 & -0.12 & $2.06 \%$ & 0.05 & -0.10 \\
\hline $\mathrm{PC}_{\text {Econ }}\left(\right.$ Adj. $\left.R^{2}\right)$ & $0.65 \%$ & 0.08 & -0.12 & $0.26 \%$ & 0.03 & -0.14 & $2.19 \%$ & 0.12 & -0.16 & $1.94 \%$ & 0.09 & -0.16 & $2.07 \%$ & 0.08 & -0.27 & $1.42 \%$ & 0.04 & -0.27 \\
\hline Mean $_{\text {Econ }}$ & $0.62 \%$ & 0.05 & 0.04 & $0.43 \%$ & 0.03 & 0.02 & $1.58 \%$ & 0.08 & 0.03 & $1.28 \%$ & 0.06 & 0.01 & $2.55 \%$ & 0.11 & 0.02 & $2.16 \%$ & 0.08 & 0.00 \\
\hline $\mathrm{PC}_{\text {Tech }}(\mathrm{SIC})$ & $1.30 \%$ & 0.11 & 0.12 & $1.26 \%$ & 0.10 & 0.13 & $2.03 \%$ & 0.11 & 0.06 & $2.18 \%$ & 0.11 & 0.09 & $1.27 \%$ & 0.05 & 0.03 & $1.36 \%$ & 0.06 & 0.05 \\
\hline $\mathrm{PC}_{\text {Tech }}\left(\operatorname{Adj} . R^{2}\right)$ & $1.11 \%$ & 0.09 & 0.09 & $0.98 \%$ & 0.08 & 0.10 & $1.81 \%$ & 0.09 & 0.04 & $1.85 \%$ & 0.09 & 0.06 & $0.87 \%$ & 0.03 & -0.01 & $0.71 \%$ & 0.03 & 0.00 \\
\hline Mean $_{\text {Tech }}$ & $0.67 \%$ & 0.06 & 0.08 & $0.59 \%$ & 0.05 & 0.09 & $1.29 \%$ & 0.06 & 0.04 & $1.41 \%$ & 0.07 & 0.06 & $1.08 \%$ & 0.04 & 0.03 & $1.20 \%$ & 0.05 & 0.04 \\
\hline $\mathrm{PC}_{\mathrm{All}}(\mathrm{SIC})$ & $1.31 \%$ & 0.13 & 0.10 & $0.90 \%$ & 0.08 & 0.10 & $3.01 \%$ & 0.17 & 0.07 & $2.77 \%$ & 0.14 & 0.09 & $4.02 \%$ & 0.18 & 0.02 & $3.50 \%$ & 0.15 & 0.04 \\
\hline $\mathrm{PC}_{\text {AII }}\left(\operatorname{Adj} . R^{2}\right)$ & $1.11 \%$ & 0.13 & 0.03 & $0.52 \%$ & 0.06 & 0.00 & $2.99 \%$ & 0.18 & 0.02 & $2.52 \%$ & 0.13 & 0.01 & $3.42 \%$ & 0.15 & -0.09 & $2.26 \%$ & 0.07 & -0.11 \\
\hline \multirow[t]{5}{*}{ Mean $_{A l l}$} & $0.68 \%$ & 0.05 & 0.06 & $0.59 \%$ & 0.04 & 0.07 & $1.41 \%$ & 0.07 & 0.05 & $1.35 \%$ & 0.07 & 0.05 & $1.80 \%$ & 0.07 & 0.04 & $1.72 \%$ & 0.07 & 0.04 \\
\hline & \multicolumn{18}{|c|}{ (b) Relative risk aversion: $\gamma=5$} \\
\hline & \multicolumn{6}{|c|}{$0 \leq w_{s} \leq 1$} & \multicolumn{6}{|c|}{$0 \leq w_{s} \leq 1.5$} & \multicolumn{6}{|c|}{$-1 \leq w_{s} \leq 2$} \\
\hline & \multicolumn{3}{|c|}{$\mathrm{c}=0$} & \multicolumn{3}{|c|}{$\mathrm{c}=50$} & \multicolumn{3}{|c|}{$\mathrm{c}=0$} & \multicolumn{3}{|c|}{$\mathrm{c}=50$} & \multicolumn{3}{|c|}{$\mathrm{c}=0$} & \multicolumn{3}{|c|}{$\mathrm{c}=50$} \\
\hline & $\begin{array}{l}\Delta \text { CER } \\
\text { (ann.) }\end{array}$ & $\Delta \mathrm{SR}$ & $\begin{array}{l}\text { Avg. } \\
\Delta \mathrm{SR}\end{array}$ & $\begin{array}{l}\Delta \text { CER } \\
\text { (ann.) }\end{array}$ & $\Delta \mathrm{SR}$ & $\begin{array}{l}\text { Avg. } \\
\Delta \text { SR }\end{array}$ & $\begin{array}{r}\Delta \text { CER } \\
\text { (ann.) }\end{array}$ & $\Delta \mathrm{SR}$ & $\begin{array}{l}\text { Avg. } \\
\Delta \text { SR }\end{array}$ & $\begin{array}{l}\Delta \text { CER } \\
\text { (ann.) }\end{array}$ & $\Delta \mathrm{SR}$ & $\begin{array}{l}\text { Avg. } \\
\Delta \text { SR }\end{array}$ & $\begin{array}{l}\Delta \text { CER } \\
\text { (ann.) }\end{array}$ & $\Delta \mathrm{SR}$ & $\begin{array}{l}\text { Avg. } \\
\Delta \mathrm{SR}\end{array}$ & $\begin{array}{l}\Delta \text { CER } \\
\text { (ann.) }\end{array}$ & $\Delta \mathrm{SR}$ & $\begin{array}{l}\text { Avg. } \\
\Delta \mathrm{SR}\end{array}$ \\
\hline $\mathrm{PC}_{\text {Econ }}(\mathrm{SIC})$ & $1.84 \%$ & 0.16 & -0.05 & $1.83 \%$ & 0.14 & -0.03 & $3.06 \%$ & 0.20 & -0.09 & $3.30 \%$ & 0.19 & -0.05 & $1.67 \%$ & 0.09 & -0.15 & $1.59 \%$ & 0.09 & -0.12 \\
\hline $\mathrm{PC}_{\text {Econ }}\left(\operatorname{Adj} . R^{2}\right)$ & $1.60 \%$ & 0.13 & -0.17 & $1.49 \%$ & 0.10 & -0.16 & $2.55 \%$ & 0.16 & -0.19 & $2.68 \%$ & 0.15 & -0.17 & $1.34 \%$ & 0.11 & -0.28 & $0.84 \%$ & 0.08 & -0.28 \\
\hline Mean $_{\text {Econ }}$ & $1.15 \%$ & 0.09 & 0.03 & $0.95 \%$ & 0.07 & 0.01 & $2.08 \%$ & 0.13 & 0.02 & $1.84 \%$ & 0.10 & 0.00 & $2.77 \%$ & 0.14 & 0.01 & $2.52 \%$ & 0.11 & 0.00 \\
\hline $\mathrm{PC}_{\text {Tесh }}(\mathrm{SIC})$ & $1.14 \%$ & 0.09 & 0.05 & $1.27 \%$ & 0.10 & 0.08 & $1.19 \%$ & 0.08 & 0.06 & $1.25 \%$ & 0.09 & 0.08 & $1.06 \%$ & 0.08 & 0.03 & $0.87 \%$ & 0.07 & 0.03 \\
\hline $\mathrm{PC}_{\text {Tech }}\left(\operatorname{Adj} . R^{2}\right)$ & $1.00 \%$ & 0.08 & 0.03 & $1.05 \%$ & 0.08 & 0.06 & $0.84 \%$ & 0.06 & 0.04 & $0.78 \%$ & 0.06 & 0.05 & $0.35 \%$ & 0.03 & -0.01 & $-0.11 \%$ & 0.01 & -0.02 \\
\hline Mean $_{\text {Tech }}$ & $0.73 \%$ & 0.06 & 0.04 & $0.83 \%$ & 0.06 & 0.06 & $0.71 \%$ & 0.05 & 0.05 & $0.73 \%$ & 0.05 & 0.06 & $0.93 \%$ & 0.06 & 0.03 & $0.80 \%$ & 0.05 & 0.02 \\
\hline $\mathrm{PC}_{A I I}(\mathrm{SIC})$ & $2.11 \%$ & 0.18 & 0.05 & $2.01 \%$ & 0.16 & 0.08 & $3.59 \%$ & 0.24 & 0.05 & $3.59 \%$ & 0.23 & 0.07 & $3.71 \%$ & 0.24 & 0.03 & $3.14 \%$ & 0.21 & 0.03 \\
\hline $\mathrm{PC}_{\text {AlI }}\left(\operatorname{Adj} . R^{2}\right)$ & $2.18 \%$ & 0.20 & 0.01 & $1.92 \%$ & 0.15 & 0.02 & $3.69 \%$ & 0.25 & 0.01 & $3.61 \%$ & 0.22 & 0.01 & $3.17 \%$ & 0.20 & -0.11 & $2.27 \%$ & 0.14 & -0.14 \\
\hline $\operatorname{Mean}_{A l l}$ & $0.93 \%$ & 0.07 & 0.05 & $0.91 \%$ & 0.07 & 0.05 & $1.34 \%$ & 0.08 & 0.05 & $1.24 \%$ & 0.07 & 0.04 & $1.79 \%$ & 0.09 & 0.04 & $1.64 \%$ & 0.07 & 0.03 \\
\hline
\end{tabular}


Table A.VI: Continued

\begin{tabular}{|c|c|c|c|c|c|c|c|c|c|c|c|c|c|c|c|c|c|c|}
\hline & \multicolumn{18}{|c|}{ (c) Relative risk aversion: $\gamma=7$} \\
\hline & \multicolumn{6}{|c|}{$0 \leq w_{s} \leq 1$} & \multicolumn{6}{|c|}{$0 \leq w_{s} \leq 1.5$} & \multicolumn{6}{|c|}{$-1 \leq w_{s} \leq 2$} \\
\hline & \multicolumn{3}{|c|}{$\mathrm{c}=0$} & \multicolumn{3}{|c|}{$c=50$} & \multicolumn{3}{|c|}{$\mathrm{c}=0$} & \multicolumn{3}{|c|}{$\mathrm{c}=50$} & \multicolumn{3}{|c|}{$\mathrm{c}=0$} & \multicolumn{3}{|c|}{$\mathrm{c}=50$} \\
\hline & $\begin{array}{l}\Delta \text { CER } \\
\text { (ann.) }\end{array}$ & $\Delta \mathrm{SR}$ & $\begin{array}{l}\text { Avg. } \\
\Delta \text { SR }\end{array}$ & $\begin{array}{l}\Delta \text { CER } \\
\text { (ann.) }\end{array}$ & $\Delta \mathrm{SR}$ & $\begin{array}{l}\text { Avg. } \\
\Delta \text { SR }\end{array}$ & $\begin{array}{l}\Delta \text { CER } \\
\text { (ann.) }\end{array}$ & $\Delta \mathrm{SR}$ & $\begin{array}{l}\text { Avg. } \\
\Delta \text { SR }\end{array}$ & $\begin{array}{l}\Delta \text { CER } \\
\text { (ann.) }\end{array}$ & $\Delta \mathrm{SR}$ & $\begin{array}{l}\text { Avg. } \\
\Delta \text { SR }\end{array}$ & $\begin{array}{l}\Delta \text { CER } \\
\text { (ann.) }\end{array}$ & $\Delta \mathrm{SR}$ & $\begin{array}{l}\text { Avg. } \\
\Delta \text { SR }\end{array}$ & $\begin{array}{l}\Delta \text { CER } \\
\text { (ann.) }\end{array}$ & $\Delta \mathrm{SR}$ & $\begin{array}{l}\text { Avg. } \\
\Delta \mathrm{SR}\end{array}$ \\
\hline $\mathrm{PC}_{\text {Econ }}(\mathrm{SIC})$ & $2.07 \%$ & 0.20 & -0.08 & $2.21 \%$ & 0.19 & -0.05 & $2.70 \%$ & 0.21 & -0.09 & $2.95 \%$ & 0.22 & -0.05 & $0.57 \%$ & 0.10 & -0.15 & $0.45 \%$ & 0.10 & -0.13 \\
\hline $\mathrm{PC}_{\text {Econ }}\left(\operatorname{Adj} . R^{2}\right)$ & $1.75 \%$ & 0.16 & -0.19 & $1.82 \%$ & 0.15 & -0.17 & $2.18 \%$ & 0.18 & -0.19 & $2.28 \%$ & 0.18 & -0.16 & $0.50 \%$ & 0.15 & -0.28 & $-0.06 \%$ & 0.13 & -0.27 \\
\hline Mean $_{E c o n}$ & $1.38 \%$ & 0.12 & 0.02 & $1.20 \%$ & 0.10 & 0.00 & $2.08 \%$ & 0.15 & 0.01 & $1.90 \%$ & 0.11 & 0.00 & $2.52 \%$ & 0.15 & 0.01 & $2.44 \%$ & 0.12 & 0.00 \\
\hline $\mathrm{PC}_{\text {Tech }}(\mathrm{SIC})$ & $0.87 \%$ & 0.09 & 0.06 & $0.95 \%$ & 0.09 & 0.08 & $1.03 \%$ & 0.10 & 0.06 & $0.93 \%$ & 0.09 & 0.06 & $0.85 \%$ & 0.09 & 0.03 & $0.59 \%$ & 0.07 & 0.01 \\
\hline $\mathrm{PC}_{\text {Tech }}\left(\right.$ Adj. $\left.R^{2}\right)$ & $0.67 \%$ & 0.06 & 0.04 & $0.66 \%$ & 0.06 & 0.05 & $0.55 \%$ & 0.06 & 0.03 & $0.31 \%$ & 0.05 & 0.03 & $-0.01 \%$ & 0.03 & -0.02 & $-0.54 \%$ & - & -0.04 \\
\hline Mean $_{\text {Tech }}$ & $0.52 \%$ & 0.05 & 0.05 & $0.56 \%$ & 0.05 & 0.06 & $0.75 \%$ & 0.07 & 0.05 & $0.66 \%$ & 0.06 & 0.05 & $0.75 \%$ & 0.06 & 0.03 & $0.60 \%$ & 0.05 & 0.02 \\
\hline $\mathrm{PC}_{A I l}(\mathrm{SIC})$ & $2.39 \%$ & 0.23 & 0.04 & $2.40 \%$ & 0.22 & 0.07 & $3.40 \%$ & 0.29 & 0.05 & $3.28 \%$ & 0.28 & 0.06 & $2.61 \%$ & 0.25 & 0.02 & $1.97 \%$ & 0.22 & 0.01 \\
\hline $\mathrm{PC}_{\text {All }}\left(\operatorname{Adj} . R^{2}\right)$ & $2.46 \%$ & 0.24 & 0.01 & $2.38 \%$ & 0.21 & 0.02 & $3.39 \%$ & 0.28 & -0.01 & $3.34 \%$ & 0.26 & -0.01 & $2.29 \%$ & 0.23 & -0.12 & $1.40 \%$ & 0.17 & -0.16 \\
\hline $\operatorname{Mean}_{A l l}$ & $0.92 \%$ & 0.08 & 0.05 & $0.86 \%$ & 0.07 & 0.04 & $1.34 \%$ & 0.09 & 0.05 & $1.22 \%$ & 0.07 & 0.04 & $1.76 \%$ & 0.11 & 0.04 & $1.67 \%$ & 0.09 & 0.03 \\
\hline
\end{tabular}

Notes: The Table reports portfolio performance measures for a mean-variance investor under alternative specifications. $\Delta$ CER denotes the annualized certainty equivalent return gain of predictive regression forecasts and $\Delta \mathrm{SR}$ is the annualized Sharpe ratio defined as the average portfolio excess return divided by the sample standard deviation both in comparison to the historical average forecast over the evaluation period 1966:01-2014:12. Avg. $\Delta$ SR indicates the average of differences in the generated Sharpe ratios using the rolling-recursive estimation setting described in section 3.4. Conditional volatility forecasts are based on an AR(1) process of stock returns realized volatility. 